\title{
Satellite observations reveal thirteen years of reservoir filling strategies, operating rules, and hydrological alterations in the Upper Mekong River Basin
}

\author{
Dung Trung Vu ${ }^{1}$, Thanh Duc Dang ${ }^{1,2}$, Stefano Galelli ${ }^{1}$, and Faisal Hossain ${ }^{3}$ \\ ${ }^{1}$ Pillar of Engineering Systems and Design, Singapore University of Technology and Design, Singapore \\ ${ }^{2}$ Department of Civil and Environmental Engineering, University of South Florida, Tampa, FL, USA \\ ${ }^{3}$ Department of Civil and Environmental Engineering, University of Washington, Seattle, WA, USA \\ Correspondence: Stefano Galelli (stefano_galelli@sutd.edu.sg)
}

\begin{abstract}
The current situation in the Lancang-Mekong River Basin is emblematic of the issues faced by many transboundary basins around the world: riparian countries prioritize national water-energy policies and provide limited information on how major infrastructures are operated. In turn, such infrastructures and their management become a source of controversy. Here, we turn our attention to the Upper Mekong River, or Lancang, where a system of eleven mainstream dams controls about 55\% of the annual flow to Northern Thailand and Laos. Yet, assessing their actual impact is a challenging task because of the chronic lack of data on reservoir storage and dam release decisions. To overcome this challenge, we focus on the ten largest reservoirs and leverage satellite observations to infer 13-year time series of monthly storage variations. Specifically, we use area-storage curves (derived from a Digital Elevation Model) and time series of water surface area, which we estimate from Landsat images through a novel algorithm that removes the effects of clouds and other disturbances. We also use satellite radar altimetry data (Jason) to validate the results obtained from satellite imagery. Our results describe the evolution of the hydropower system and highlight the pivotal role played by Xiaowan and Nuozhadu reservoirs, which make up to $~ 85 \%$ of the total system's storage in the Lancang River Basin. We show that these two reservoirs were filled in only two years, and that their operations did not change in response to the drought that occurred in the region in 2019-2020. Deciphering these operating strategies could help enrich existing monitoring tools and hydrological models, thereby supporting riparian countries in the design of more cooperative water-energy policies.
\end{abstract}

\section{Introduction}

In many transboundary river basins, conflicting dynamics between riparian countries are typically the result of different views on infrastructure development and management (Warner and Zawahri, 2012). Such dynamics are often compounded by the lack of transparency on how major infrastructure, such as dams, are operated. The situation in the Lancang-Mekong River 
basin is no exception: during the past three decades, the basin has witnessed a rapid development of its hydropower fleet (Chowdhury et al., 2021), which has altered the hydrological regime (Dang et al., 2016; Räsänen et al., 2017) and changed the sediment budget (Kondolf et al., 2018; Binh et al., 2020), thereby degrading riverine ecosystems and threatening riparian communities (Sabo et al., 2017; Soukhaphon et al., 2021). In turn, these profound and ramified changes have challenged the relation between riparian countries (Wei et al., 2021). In this water-energy management 'mishmash', China plays a critical role. First, the river originates in the Tibetan Plateau and flows within the Chinese borders for about $2000 \mathrm{~km}$, creating a natural power asymmetry with the other riparian countries (Kattelus et al., 2015). Second, China has built a limited number of dams - only eleven out of the hundred, or more, that currently punctuate the entire basin (Hecht et al., 2019). Yet, these few dams in the Upper Mekong River, or Lancang, have massive storage capacity $\left(\sim 42 \mathrm{~km}^{3}\right)$ and control a sizeable portion of the river discharge (about 55\% of the average annual flow measured in Northern Thailand). Third, China has participated fairly weakly in transboundary water cooperation efforts, prioritizing bilateral cooperation to multi-country engagements, such as the Mekong River Commission (Kattelus et al., 2015; Williams, 2020). Fourth, China has yet to share detailed and comprehensive data on dam operations; agreements on data sharing and quality control are only at their infancy (Johnson, 2020). Because of these reasons, the Lancang's dams have become a source of controversy between China and downstream countries (IRN, 2002; Eyler and Weatherby, 2020; Kallio and Fallon, 2020). But to assess their actual impact and inform cooperative efforts, we must first quantify and understand how these dams have been operated.

There are at least two approaches available to tackle this challenge. The first one builds on the idea of generating data on reservoir inflow, storage, and release via simulation with a process-based hydrological-water management model; a solution recently explored for the Mekong Basin by Dang et al. (2020a), Yun et al. (2020), and Shin et al. (2020). Naturally, this is only a partial fix, since the simulation of water reservoir storage and operations still requires some basic information on design specifications and operational strategies. The second approach relies on satellite remote sensing, which provides a means to directly observe a few key variables. Satellite altimeters, for example, provide high resolution water level data of lakes and reservoirs (Schwatke et al., 2015; Busker et al., 2019; Biswas et al., 2019), while optical satellite images can be processed to map and detect changes in water surface area (Pekel et al., 2016; Zhao and Gao, 2018; Pickens et al., 2020). Moreover, data on water level and area can be combined with information on bathymetry (e.g., elevation-area curve) to infer the storage time series (see the review by Gao (2015)). The widespread availability of satellite data has indeed sparked research on monitoring of reservoir operations in several ungauged basins across the globe (Gao et al., 2012; Duan and Bastiaanssen, 2013; Bonnema et al., 2016; Busker et al., 2019), including the Mekong River Basin. For example, Liu et al. (2016) used satellite radar altimetry and Landsat images to estimate the water level of two reservoirs in the Lancang (Xiaowan and Jinghong) for the period 2000-2015. Their analysis was limited to cloudless Landsat images, so the time series so-derived have an irregular temporal resolution. Shortly after, Bonnema and Hossain $(2017,2019)$ estimated reservoir storage change for several sites of the Mekong, focussing primarily on its lower reaches.

Importantly, the aforementioned approaches and data have started to find their way into decision support systems used by the Lower Mekong countries. A first example is the Mekong Dam Monitor, an online platform for near-real time monitoring of dams developed by the Stimson Center and Eyes on Earth (https://www.stimson.org/project/mekong-dam-monitor/). Specifi- 
cally, the platform uses Sentinel 1 and 2 images to provide weekly updates of water level in the thirteen dams built on the main stem—plus fourteenth additional reservoirs on the river tributaries (Eyler et al., 2020). Because Sentinel 1 and 2 were launched in April 2014 and June 2015, respectively, the available time series are relatively short and do not include the filling period of the two largest Lancang's reservoirs, Nuozhadu and Xiaowan. Another example is the Reservoir Assessment Tool (RAT, https://depts.washington.edu/saswe/rat_beta/), an online tool for near real-time monitoring and impact analysis of existing and planned reservoirs (Biswas et al., 2021). RAT uses Landsat 5 and 8 images to monitor $\sim 1,500$ reservoirs in South America, Africa, and Southeast Asia, including six in the Lancang River Basin.

Notwithstanding these recent advances, a deeper understanding of dam operations in the Lancang River Basin is needed to inform the downstream countries and seek cooperative solutions spanning across the entire basin. A first complexity is the lack of water level and storage time series (for each reservoir in the Lancang Basin) with adequate temporal resolution and horizon-ideally, each time series should have at least a data point per month and cover the entire life span of a given dam. Here, an important challenge lies with data availability: Landsat images are available for almost any reservoir and span more than three decades, but are affected by clouds (Busker et al., 2019; Biswas et al., 2021), thereby requiring an image enhancement process (Gao et al., 2012; Zhang et al., 2014; Avisse et al., 2017). Conversely, satellite altimeter observations are less subject to external disturbances. However, they either have sparse spatial coverage (satellite radar altimeters)—data are not available for all reservoirs due to their narrow ground track and orbit—or have a long revisit time (satellite laser altimeters). The ICESat series (satellite laser altimeters), for example, has a 91-day return period. Second, we need to discover the filling strategy of these dams, that is, the rate with which they have been filled. Unveiling these strategies could help understand past changes in downstream water availability and prepare contingency plans, since China is planning to build ten more dams in the Lancang (MRC, 2020b). Third, the availability of monthly storage data is the prerequisite for any event attribution analysis on droughts and pluvials. In other words, detailed information on the operations of the Lancang's dams could help us explain how they contributed to recent extreme events.

In this study, we address the three knowledge gaps described above. To this purpose, we rely on a $30 \mathrm{~m}$ Digital Elevation Model (DEM) from the Shuttle Radar Topography Mission (SRTM), satellite imagery (Landsat 5, 7, and 8) and altimetry data (Jason 2 and 3) (Section 2). In particular, we use the DEM data to identify the elevation-storage and area-storage curves and process the Landsat images to generate monthly time series of water surface area for each reservoir. In this analysis, we improve the algorithm introduced by Gao et al. (2012) and modified by Zhang et al. (2014) for processing cloudy images and tailor it to Landsat data. We then infer the time series of reservoir storage by combining information on water surface area and areastorage curve, and validate the results using the altimetry data with the elevation-storage curve (Section 3). With the storage time series at hand, we unveil the filling strategies, infer the rule curves, and relate the downstream hydrological alterations to the reservoir management strategies (Section 4). Building on this knowledge, we identify and discuss opportunities for improving the management of the Lower Mekong resources under present and future scenarios (Section 5 and 6). 


\section{Study Site and Data}

\subsection{Study Site}

The Mekong is a transboundary river flowing across Southwest China and Southeast Asia (Figure 1(a)). The river originates from the Tibetan Plateau at an altitude of about $5200 \mathrm{~m}$ a.s.l. and flows in a northwest-southeast direction through six countries (China, Myanmar, Laos, Thailand, Cambodia, and Vietnam) before pouring into the East Vietnam Sea. The Mekong drains an area of 795,000 $\mathrm{km}^{2}$ with an average annual discharge of approximately $475 \mathrm{~km}^{3}$. Its upper portion is $2140-\mathrm{km}$ long and drains an area of $176,400 \mathrm{~km}^{2}$. The high mountains and low valleys characterizing the Lancang River Basin contribute to the spatial variability of precipitation, whose annual average varies from 750 to $1025 \mathrm{~mm}$ across the basin. Precipitation is also unevenly distributed across the year, with two distinct dry (December to May) and wet (June to November) seasons. The streamflow reflects a similar seasonal pattern (Yun et al., 2020). Although the drainage area of the Lancang River accounts for about 22\% of the total catchment area, the Lancang contributes only to $16 \%$ of the average annual discharge of the whole Mekong River (MRC, 2009).

The advantageous topography and abundant water availability make the Lancang River Basin an ideal spot for the hydropower industry (Dang et al., 2020a). The first dam on the mainstream of the Lancang (Manwan) began its operations in 1992, followed by Dachaoshan in 2003 and Jinghong in 2008. The two largest dams (Xiaowan and Nuozhadu) became operational in 2009 and 2013, respectively. And since 2016, at least one dam joined the Lancang's reservoir system every year. Overall, this rapid transformation of the basin resulted in a system comprising eleven operational and one planned dam (Figure 1(b)).

The design of the cascade reservoir system reflects the topographic characteristics of the basin. Specifically, the presence of narrow valleys with steep sides required the construction of high dams (see Figure 2 and the list of design specifications in Table S1). In turn, this resulted in reservoirs with large storage capacity relative to inflow, steep banks, and long and horizontally narrow shapes. The total storage capacity is $42,170 \mathrm{Mm}^{3}$, about $55 \%$ of the average annual discharge at Chiang Saen gauging station, the first downstream station with publicly-available data (Figure 1). These reservoirs form a long and complex cascade system, so it is only by studying it in its entirety that we can understand how storage operating patterns has evolved over the past decade.

\subsection{Data}

In this study, we focus on the ten largest operational reservoirs (each with a volume larger than $100 \mathrm{Mm}^{3}$ ), all located on the main stem of the Lancang River. We select 2008-2020 as our study period because it includes the year of commission of most dams (eight out of ten); a choice that allows us to study their operations during the filling period as well as under regular operating conditions. Extending the temporal horizon to include the year of commission of the two remaining dams (Manwan and Dachaoshan, commissioned in 1992 and 2003) would complicate the analysis unnecessarily, since their aggregated storage capacity corresponds to only $2.14 \%$ of the current total system capacity. For the aforementioned study period we gathered data on Digital Elevation Model (DEM), satellite imagery, and radar altimetry. 

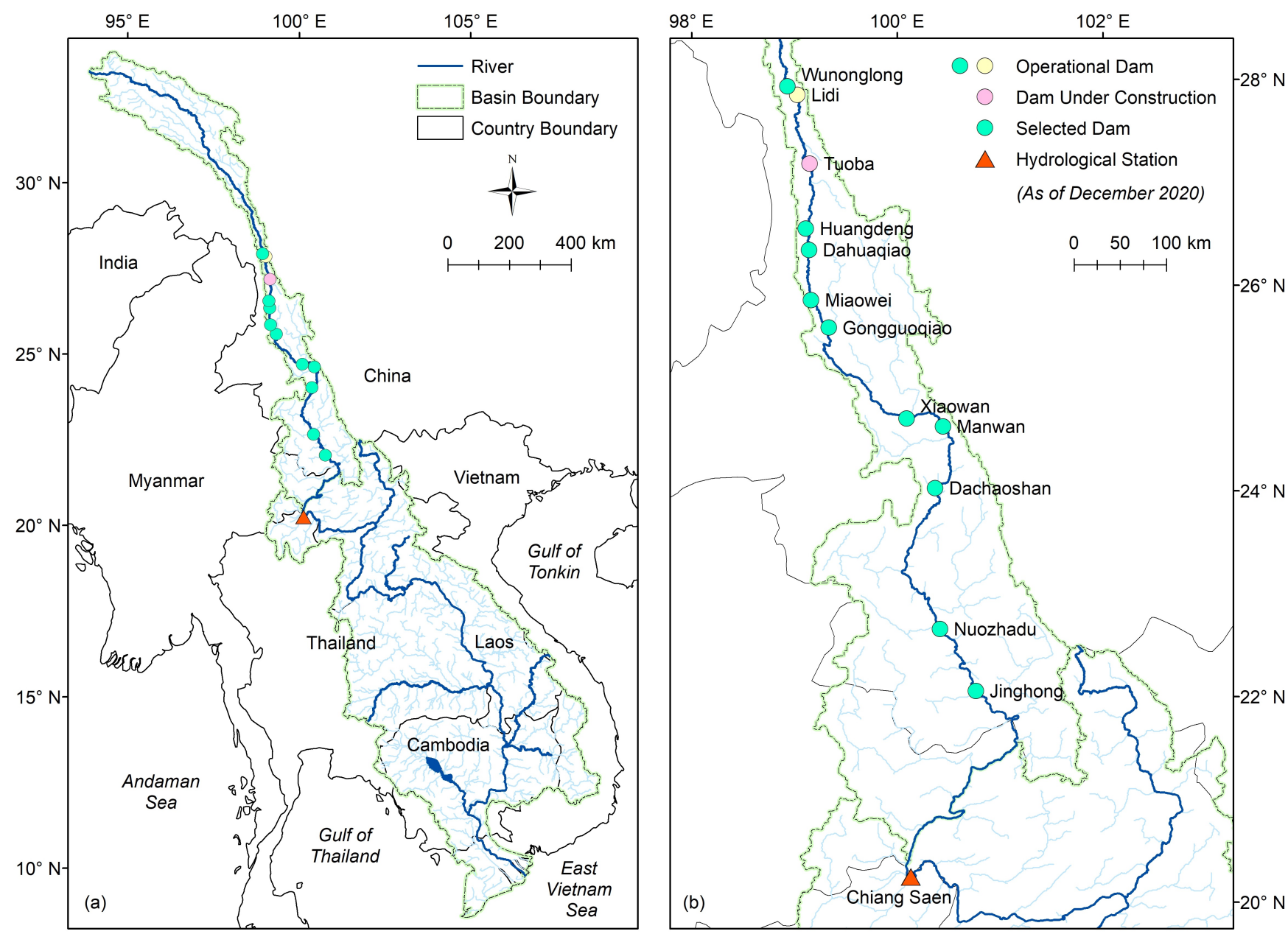

Figure 1. Mekong and Lancang River Basins ((a) and (b), respectively). In both maps we report the location of the gauging station as well as the hydropower dams on the main stem of the Lancang. All dams were operational as of December 2020, with the exception of Tuoba, which is currently under construction. The dams analyzed in our study are denoted by a green circle.

\subsubsection{Digital elevation model}

Digital elevation models contain the information on terrain elevation needed to represent reservoir bathymetry, so they are commonly used to establish the relationship between water level and water surface area (Bonnema et al., 2016; Zhang and Gao, 2020). In this study, we use the global 30-m resolution DEM obtained by the Shuttle Radar and Topography Mission (SRTM). The SRTM-DEM provides the terrain elevation above the water level at the observation time of the SRTM mission (February 2000) in signed integer raster format. The SRTM-DEM is the best choice for representing reservoir bathymetry on the Lancang River because of its high spatial resolution, acquisition time (nine out of ten selected reservoirs were constructed after February 2000), and free accessibility. 


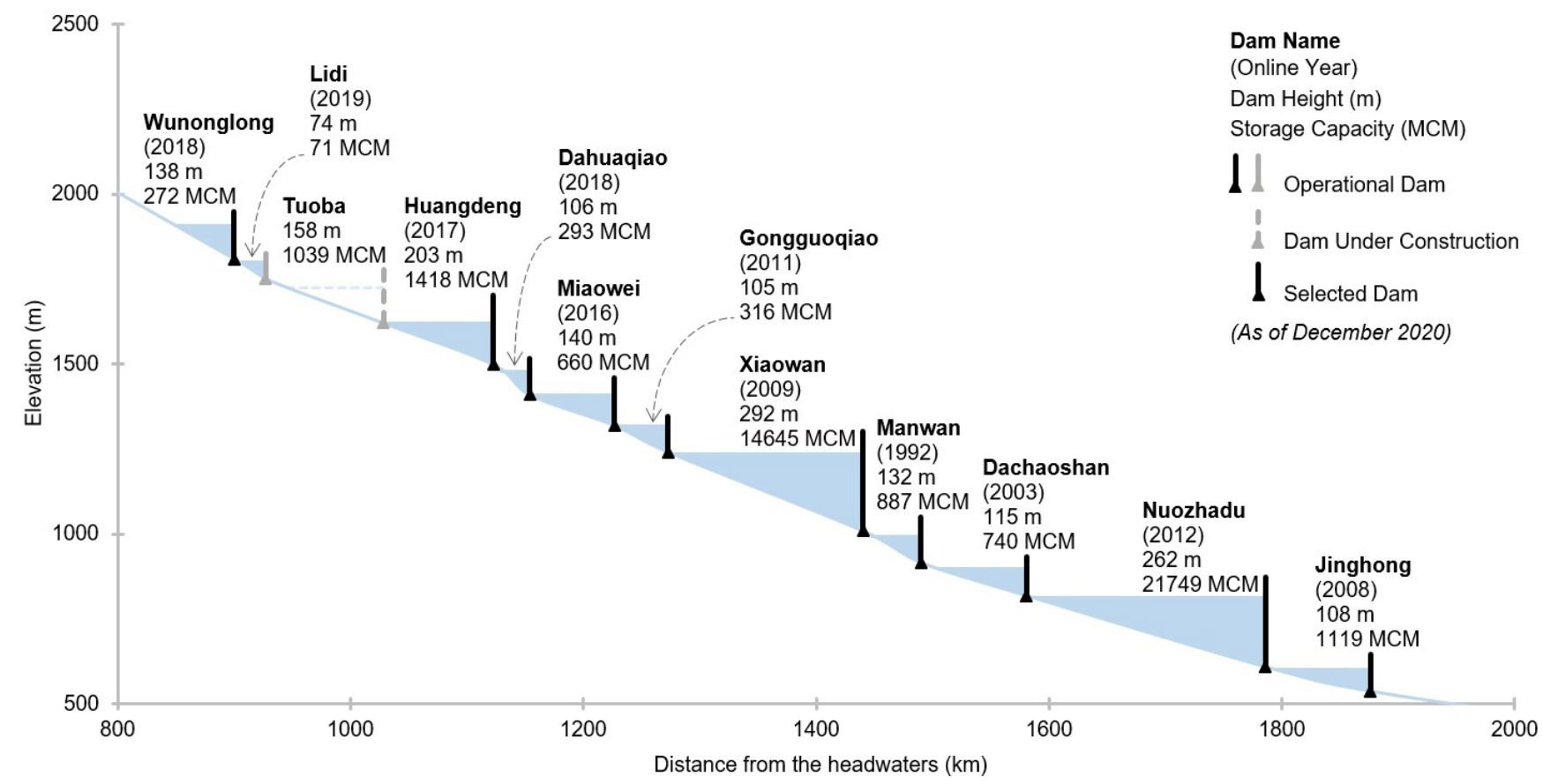

Figure 2. Cascade reservoir system on the Lancang River. Further details about the design specifications are provided in Table S1.

\subsubsection{Satellite Imagery}

We use images from Landsat 5, 7, and 8 to estimate the water surface area of the Lancang reservoirs. That is because of four reasons. First, Landsat imagery has been collected for a long time, so it covers our study period. Second, Landsat images have a high spatial resolution $(30 \mathrm{~m})$, which is suitable to detect changes in the water surface area of reservoirs with long and horizontally narrow shapes, like the ones in our study site. For instance, the width (at full capacity) of Nuozhadu and Xiaowan reservoirs, the two largest reservoirs on the Lancang River, is only $\sim 1500$ and $\sim 1000 \mathrm{~m}$. Third, the frequency of Landsat imagery (16 days) is enough to assess the change of reservoir water surface area with a monthly time step-a reasonable temporal resolution for reservoirs characterized by massive storage capacities. Moreover, we can double the number of images for each month, because the active period of Landsat 7 (1999-present) overlaps with the active period of Landsat 5 (19842013) and Landsat 8 (2013-present). Fourth, Landsat imagery has been successfully used in other studies to estimate reservoir water surface area (e.g., Duan and Bastiaanssen (2013), Avisse et al. (2017), Bonnema and Hossain (2017)). It is also worth mentioning here that (publicly available) imagery provided by other missions, such as MODIS (Moderate Resolution Imaging Spectroradiometer) and Sentinel, may not be best suited for this study. MODIS imagery has high frequency (twice a day) but lower spatial resolution $(250 \mathrm{~m})$, which makes it unsuitable for estimating the water surface area of medium and small reservoirs or large, but horizontally narrow, reservoirs. Meanwhile, Sentinel has been operational since 2015, so its temporal 
coverage is not sufficiently long for our analysis. Further details concerning a comparison between Landsat, MODIS, and Sentinel imagery are reported in Table S2.

\subsubsection{Radar Altimetry Data}

Satellite radar altimeters have been used for decades to monitor the ocean and large reservoirs and lakes (Schwatke et al., 2015) - see Table S3 for additional details on satellite altimeters. Because radar altimetry data from each satellite are not available for all reservoirs, we make use of all available sources of radar altimetry data. Specifically, we use Jason-2 satellite altimetry data (2008-2016) for Nuozhadu and Xiaowan reservoirs, and Jason-3 satellite altimetry data (2016-2020) for Xiaowan reservoir. As we shall see, the lack of Jason series altimetry data for the remaining reservoirs does not affect the conclusions of our study, since we use water levels from altimetry data only for the purpose of validating the results obtained through satellite imagery.

\section{Methodology}

Our methodology consists of three main steps, illustrated in Figure 3. We begin by processing the information contained in the DEM to estimate the relationship between water level (WL) and water surface area (WSA) for each reservoir. With this relationship, also called the elevation-area (E-A) curve, we calculate the elevation-storage (E-S) curve (the relationship between WL and storage volume) and the area-storage (A-S) curve (the relationship between WSA and storage volume). Then, we estimate the WSA of each reservoir from all Landsat images available for our study period. To carry out this step, we rely on a novel variant of the WSA estimation algorithm developed by Gao et al. (2012) and modified by Zhang et al. (2014). Finally, we use the A-S curves and WSA time series to infer how the storage of each reservoir varied during the study period. To validate our analysis for the two largest reservoirs (Nuozhadu and Xiaowan), we re-estimate the reservoir storage using the E-S curve and altimetry data. A detailed explanation of our methodology is provided in Section 3.1 and 3.2.

\subsection{Estimating the E-A, A-S, and E-S curves}

Recall that for nine, out of ten, reservoirs, the SRTM-DEM can provide full information on bathymetry (Section 2.2). To estimate the E-A curve of these reservoirs, we first isolate the DEM data with the contour corresponding to maximum water level and dam crest line. Then, we calculate the surface area corresponding to each 1-m elevation of the DEM. We finally fit a five-degree polynomial (degree determined by trial-and-error) to the data points so obtained. For the remaining reservoir, Manwan, we apply the same procedure, but only to the portion above the water level recorded by the SRTM. To approximate the E-A curve below that water level, we fit a five-degree polynomial to the part above the water surface and then extend it below the water surface, as in Bonnema et al. (2016); Bonnema and Hossain (2017).

With the E-A curve at hand, we calculate the storage volume corresponding to each 1-m elevation of the DEM. This operation is carried out using the following trapezoidal approximation (Gao et al., 2012; Bonnema and Hossain, 2019; Li et al., 2019; 


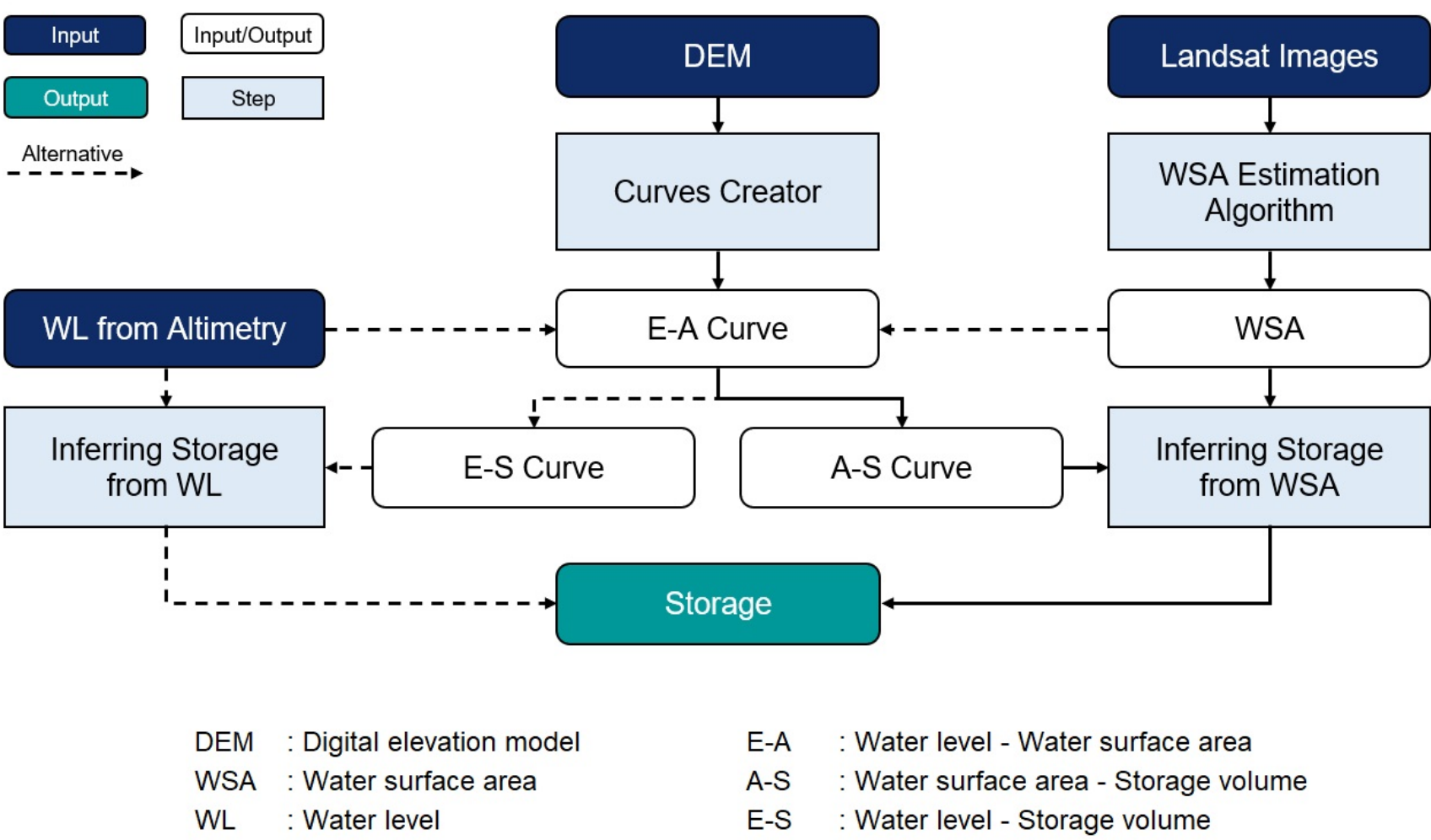

Figure 3. Flowchart representing our methodological approach. The two key steps are the calculation of of the E-A, E-S, and A-S curves (from the DEM) and the estimation of the WSA (from Landsat imagery). With this information at hand, we estimate the storage time series of each reservoir. The altimetry data are coupled with the E-S curve to re-estimate the storage time series with independent data, thereby validating the estimation based on Landsat imagery.

Tortini et al., 2020):

$V_{i}=\sum_{j=l+1}^{i}\left(A_{j}+A_{j-1}\right)\left(E_{j}-E_{j-1}\right) / 2$,

where $V_{i}$ is the storage volume corresponding to the water level $E_{i}$ and water surface area $A_{i}$, while $l$ denotes the lowest elevation of the reservoir bathymetry (i.e., $A_{l}=0$ ). Finally, we use the data points on storage volume to fit the A-S and E-S curves. All the aforementioned operations are carried out in Python 3.7 with the aid of the OSGeo library.

\subsection{Inferring the water surface area}

Water surface data can be inferred from Landsat images by classifying each pixel with either a single spectral band (e.g., near-infrared band) or a spectral index calculated from multiple bands (see Table S4 for a list of the most common indices). In general, the use of a single spectral band reduces the computational requirements ( $\mathrm{Li}$ et al., 2019), but spectral indices tend 
to provide more robust results (Liu et al., 2016). Whatever the method used, one key challenge with Landsat images stands in the presence of clouds, cloud shadow, and no-data pixels (for Landsat 7), which may lead to a misclassification of water pixels and the consequent underestimation of the water surface area. To handle this problem, we use a novel variant of the WSA estimation algorithm introduced by Gao et al. (2012) and Zhang et al. (2014), originally conceived to extract water surface area from the Normalized Difference Vegetation Index (NDVI) layer-which is included in the 250 m-resolution global Terra MODIS Vegetation Indices (MOD13Q1), a level-3 MODIS product provided by NASA.

Like the modified version by Zhang et al. (2014), our algorithm consists of two main phases: mask creation and water classification improvement, illustrated in Figure 4 with light blue and light green boxes. In the first phase, the cloudless images are processed together to create two products, the expanded mask and zone mask. The two masks are then used in the second phase, where the Landsat images are individually processed to obtain the water surface area corresponding to the collection time of each image. The major modifications with respect to the version by Zhang et al. (2014) are the selection of cloudless images (Step 1.1) and identification of additional water zones (Step 2.5); two modifications needed to ensure that the algorithm performs well with Landsat images (instead of the NDVI layer of MOD13Q1). Further details for each phase and step are provided below.

[1.1] Selection of cloudless images. Cloudless images are the ones that do not contain clouds or contain very little clouds on the reservoir surface extent. For our application, we define a cloudless image as an image with less than $20 \%$ of cloud cover on the maximum reservoir surface extent. To identify these images, we use the BQA band (the band of quality assessment), which contains the information on cloud pixels. As we shall see, working on a subset of cloudless Landsat images is necessary to preserve the quality of the frequency map and masks produced in the next steps. Note that the version by Zhang et al. (2014) did not include this step because cloud effects are partially removed from the NDVI layer in MOD13Q1 (Didan and Munoz, 2019). This is the result of selecting the best available pixel value (the low clouds and the highest NDVI value) from all daily acquisitions within a 16-day period.

[1.2] NDWI-based classification. To classify the water and non-water pixels, we use the normalized difference water index (NDWI) with a threshold value equal to 0 . The choice of index and corresponding threshold is based on a preliminary analysis, in which we compared the performance of NDWI, NDVI, and MNDWI (Modified Normalized Difference Water Index) for Xiaowan reservoir. The results, reported in Figure S1 for 60 cloudless Landsat images, show that the NDWI-based classification matches the maximum water extent reported in the Maximum Water Extent dataset, developed by the European Commission's Joint Research Centre (Pekel et al., 2016). On the other hand, NDVI and MNDWI tend to provide less reliable results. As for the threshold value, 0.05 and 0.1 (for NDWI) tend to lead to an underestimation of the water pixels, since the total number of times a water pixel is correctly classified as water is less than 60. The NDWI layers so-calculated are subsequently used in Step 2.2.

[1.3] Frequency map creation. To create the frequency map, we first calculate the percentage of times in which a pixel is classified as water (based on its NDWI value) in all selected cloudless images. This operation is carried out for all pixels within the bounding box of the reservoir extent. Then, we create the frequency map by selecting the pixels with frequency larger than 0. This step is illustrated in Figure 5(a,b). 


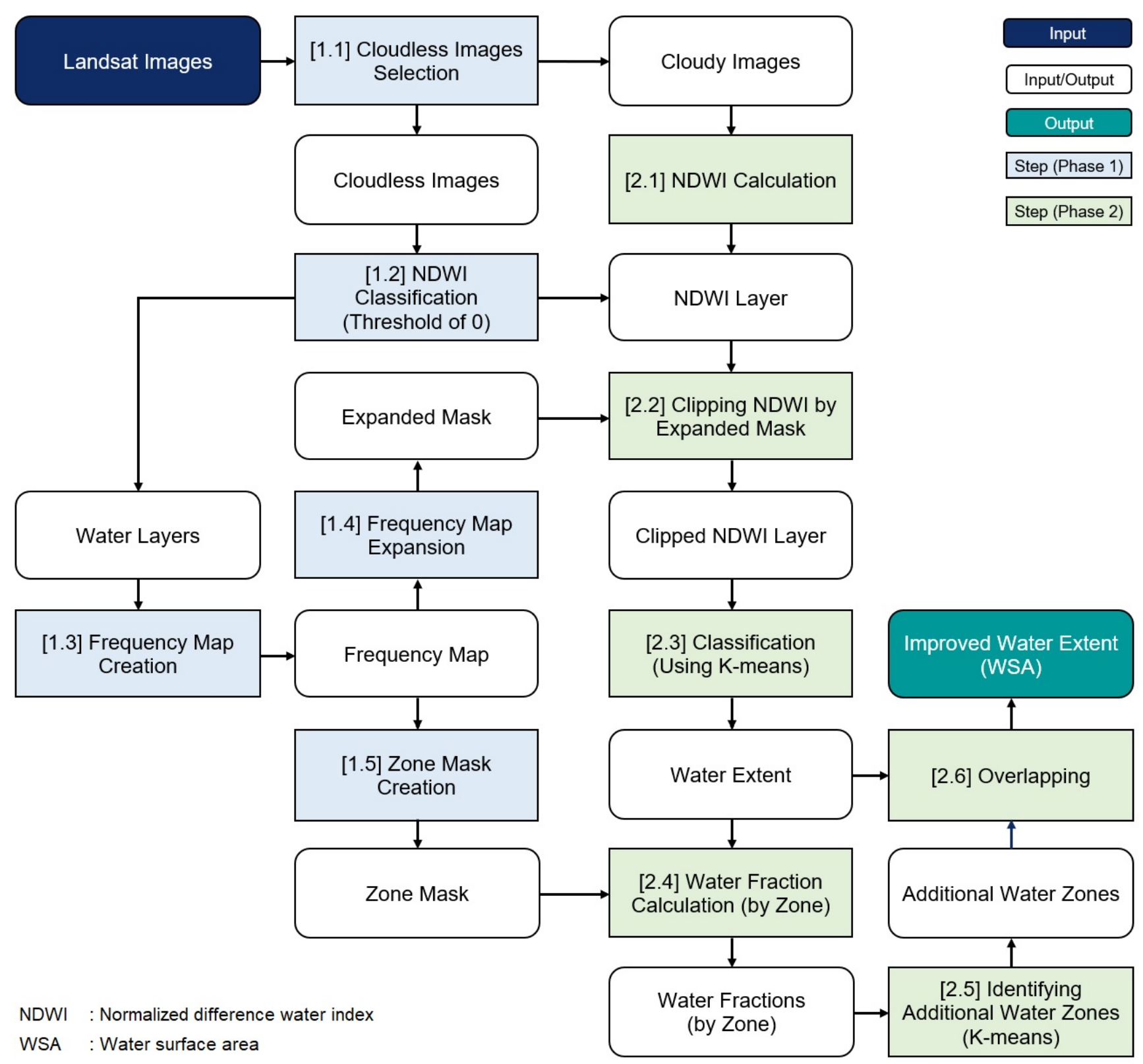

Figure 4. WSA estimation algorithm. The first phase is aimed at the creation of the expanded mask and zone mask, while the second phase focuses on the processing of each image to yield the water surface area.

[1.4] Frequency map expansion. We expand the frequency map by buffering it with three additional pixels; in other words, we add three pixels around the peripheral water pixels (see Figure 5(a,b)). The expansion is aimed to ensure that no possible water pixels are missed out. This 90-m buffer around the nominal shoreline is deemed sufficient for our case study, since reservoirs in 
the Lancang are located in steep terrains, where the storage is controlled by elevation more than area. The expanded frequency map is used in Step 2.2 to clip the NDWI layer; hereafter, we refer to it as expanded mask.

[1.5] Zone mask creation. In the last step of Phase 1, we convert the frequency map into a 50-zone mask. As illustrated in Figure 5(c), the $i$-th zone contains the pixels classified as water with a frequency greater than $2 \cdot(i-1) \%$ and less than or equal to $2 \cdot i \%$ (with $i=1, \ldots 50$ ). For example, Zone 1 contains the pixels classified as water from 0 to $2 \%$ of the time, while Zone 2 contains those classified as water from 2 to $4 \%$ of the time. At the end of this phase, we obtain the two inputs for the next phase, that is, the expanded mask and zone mask.

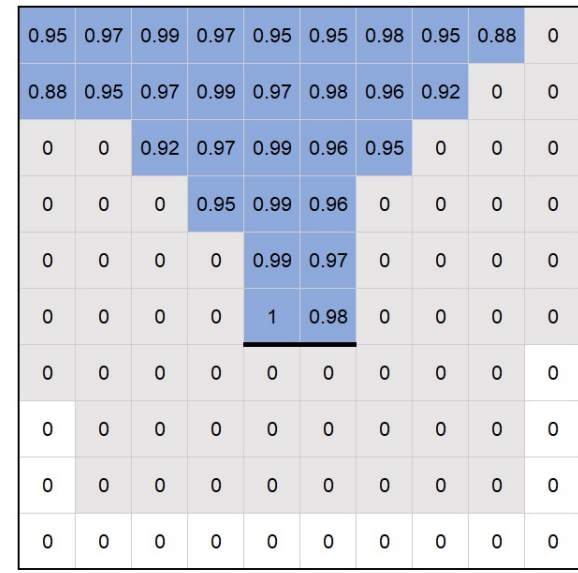

Water Pixel (with Frequency)

Extended Pixel

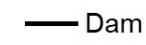

(a)

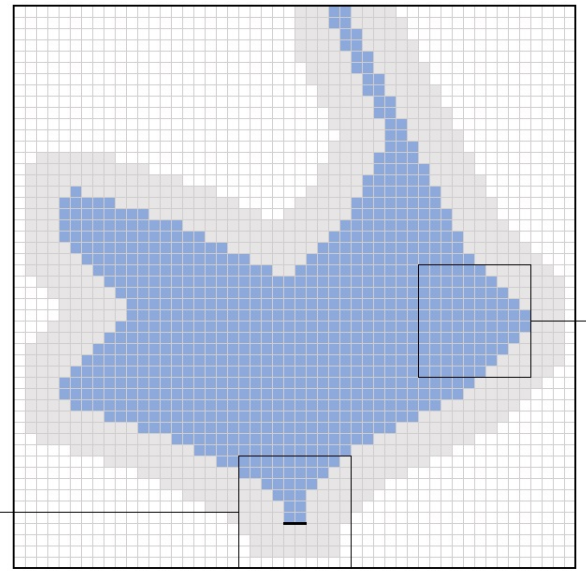

Water Pixel

Extended Pixel

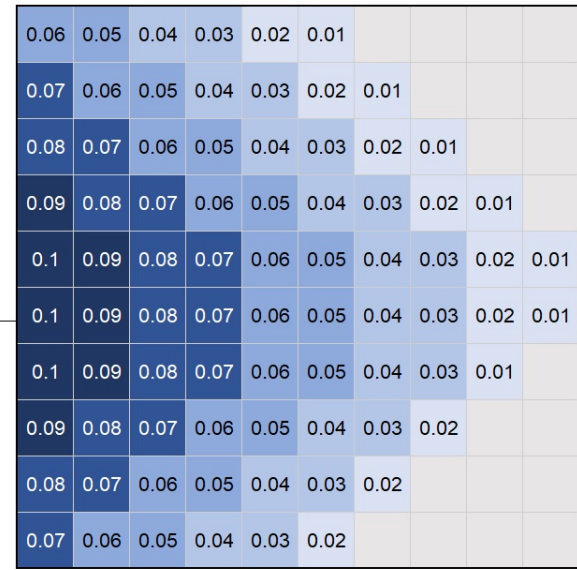

Zone 1

Zone 4

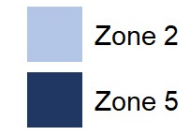

(c)

Figure 5. Example of a frequency map (a,b), expanded mask (a,b), and zone mask (c).

[2.1] NDWI calculation. Here, we calculate the NDWI index for the remaining Landsat images—with clouds, cloud shadow, and no-data pixels - and pass them to the next step in the form of a raster layer for each image. Note that the goal of this second phase is to improve the water surface classification of the images, so as to maximize the number of data points available for our study period.

[2.2] Clipping the NDWI layer by the expanded mask. The NDWI raster layer obtained in Steps 1.2 and 2.1 is clipped by the expanded mask created in Step 1.4.

[2.3] k-means-based classification of the water pixels. Because of the presence of clouds, and other disturbances, the of use of the same NDWI threshold (equal to 0) in all Landsat images may lead to overestimation or underestimation errors of the water surface area. To find NDWI thresholds for each Landsat image, we resort to $k$-means clustering. Specifically, we set $k$ equal to three (a value found by trial-and-error) and apply $k$-means clustering to all pixels in the NDWI layer (Figure 6(a)). Water pixels tend to fall into the cluster with the highest NDWI values, because the NDWI of water pixels has higher value 
than the one of non-water pixels. Results are verified by manually checking the classified water layer with true-color Landsat images.
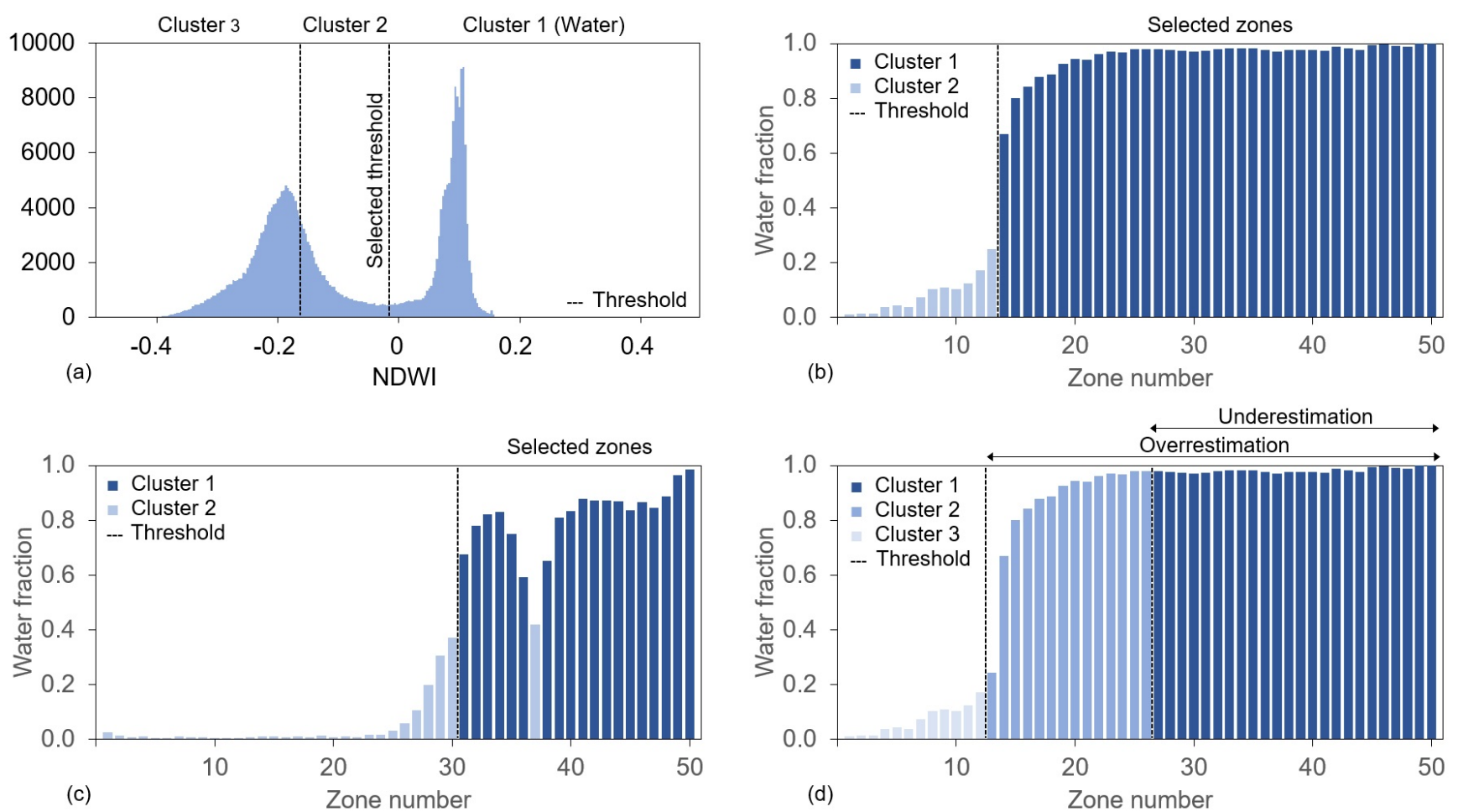

Figure 6. Illustration of the $k$-means classifications used in Step 2.3 and 2.5. Panel (a) shows the water pixels classification based on NDWI values (Step 2.3), while panels (b,c) show the identification of additional water zones based on two clusters (Step 2.5). Panel (d) illustrates the issues that raise when using three clusters in Step 2.5. (obtained in the previous step) into 50 zones. For the $i$-th zone, we define the water fraction $p_{i}$ as follows:

$p_{i}=n_{i} / N_{i}, i=1,2, \ldots, 50$,

where $p_{i}$ represents the ratio between the number $n_{i}$ of pixels classified as water in zone $i$ (with the NDWI-based $k$-means clustering) and the total number $N_{i}$ of pixels in zone $i$ (retrieved from the zone mask). The information provided by the water fraction of each zone is used in the next step to improve the water pixel classification.

[2.5] Identification of additional water zones. We improve the classification of water pixels by identifying the additional water zones based on their water fraction. To do so, we resort again to the $k$-means clustering algorithm. Moreover, because of the continuity of water extent (water expands from higher frequency to lower frequency zones), we also take into account the zone number (or frequency value). Then, we formulate a clustering problem in a two-dimensional space constituted by water fraction and zone number. We solve the clustering problem with a value of $k$ equal to two, found by trial-and-error. Figure 
6(b,c) shows two examples with $k=2$, while Figure 6(d) reports an example for an unsuitable value of $k$. The lowest zone in the higher cluster (zone 14 in Figure 6(b) and zone 31 in Figure 6(c)) is the threshold above which zones are converted to water pixels. This step represents the second modification of the original WSA estimation algorithm, which uses a quality parameter not suitable for Landsat images_-since the cloud effects are not mitigated, unlike the NDVI layer in MOD13Q1.

[2.6] Overlapping. Finally, the layer of additional water pixels is overlapped to the layer of water extent obtained in Step 2.3. The final output is the improved water classification for each image characterized by cloud cover or other disturbances. All the aforementioned operations are carried out in Python 3.7 with the aid of the OSGeo and SKLearn libraries.

\section{Results}

We begin this section by reporting the results of the analysis of DEM and satellite imagery, that is, the E-A, A-S, and E-S curves (Section 4.1) and water surface area (Section 4.2). We then present the storage time series of each reservoir, the information we use to retrieve the dam operating policies under filling and steady-state conditions (Section 4.3). Finally, we leverage these results to analyze the effect of reservoir operations on downstream discharge (Section 4.4).

\subsection{E-A, A-S, and E-S curves}

The E-A curves of Nuozhadu and Xiaowan reservoirs are illustrated in Figure 7 (panels (a) and (d)), where the blue circles represent the data points derived from the DEM, and the light blue lines are the five-degree polynomials fitted to them. Note that both curves correctly intersect the point identified by maximum water level and maximum water surface area, retrieved from Do et al. (2020). A similar evaluation is carried out for the A-S and E-S curves (Figure 7, panels (b,c,e,f)), but this time using design specifications on full storage (A-S and E-S curves) and dead storage (E-S curves).

We carry out an additional validation of the E-A curves by comparing them against observations of water level and surface area obtained from Jason radar alimetry data and Landsat imagery. These observations, illustrated in Figure 7 (a,d) by cyan diamonds, follow closely the curves identified through the DEM. Naturally, the cyan points are primarily concentrated between the dead and maximum water levels, which denote the normal range of operating conditions. As we shall see later, points below the dead water level correspond to the dam filling period.

The E-A, A-S, and E-S curves of the remaining eight reservoirs are reported in Figure S2 and S3. Because the radar altimetry data from Jason 2 and 3 are not available (Section 2.2), the only option to evaluate these curves stands in a comparison against the design specifications reported by Do et al. (2020). Such evaluation is only partially successful, since we did not find a perfect match between curves and design specifications for Jinghong, Gongguoqiao, Miaowei, Dahuqiao, and Wunonglong reservoirs. Considering that the procedure used to estimate the curves has been successfully employed in several studies (Bonnema et al., 2016; Bonnema and Hossain, 2017; Zhang and Gao, 2020), we suspect that the reason behind the mismatch may lie with the information on dam design specifications available to the public. In turn, this reinforces the need for research aimed to retrieve data on large-scale infrastructure in transboundary river basins. We also note that this source of uncertainty does not severely 

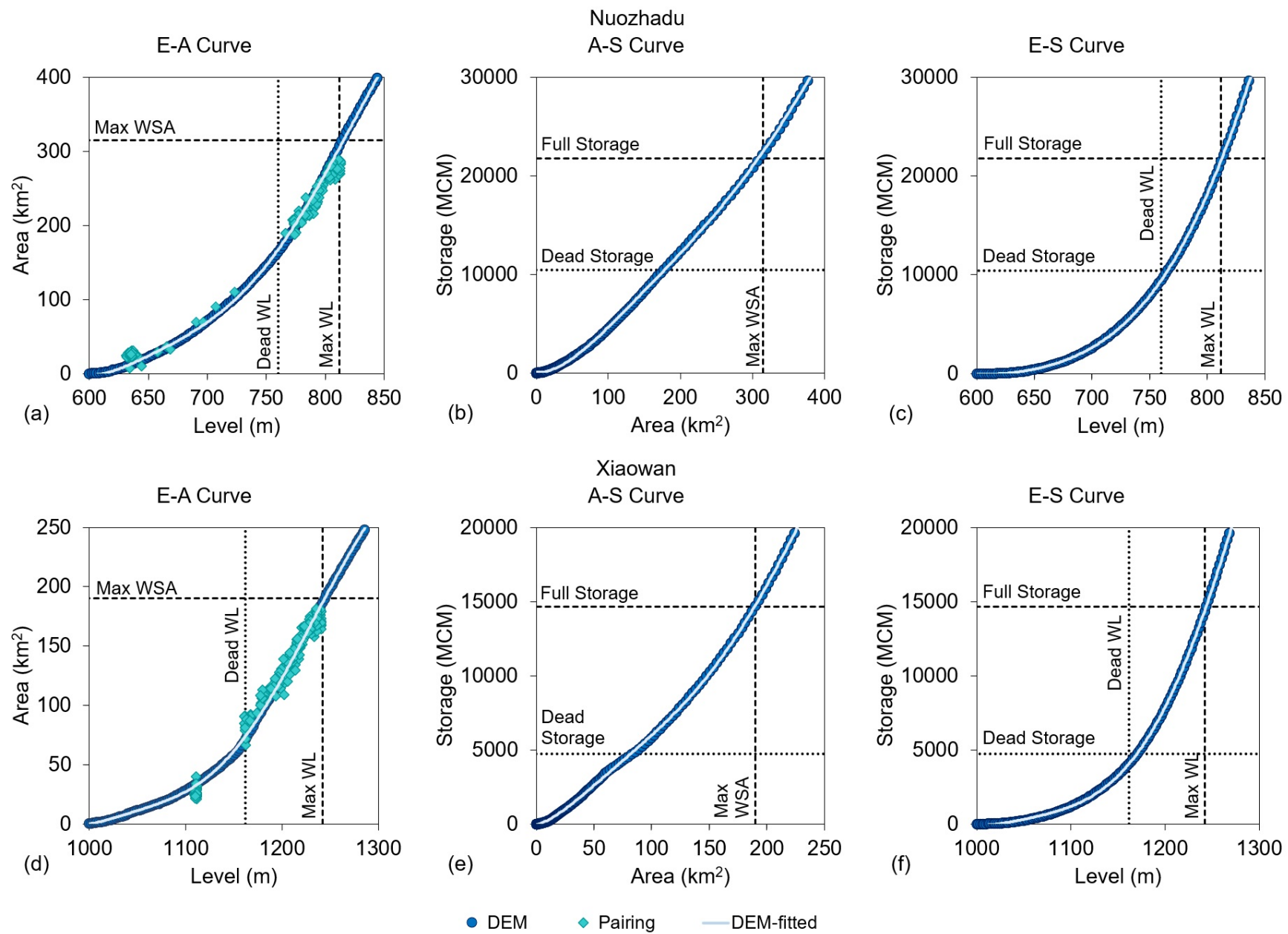

Figure 7. E-A, A-S, and E-S curves of Nuozhadu (top) and Xiaowan (bottom) reservoirs. The curves are represented by light blue lines, which are fitted to the data points (blue circles) derived from the DEM data. Note that the curves intersect the points identified by maximum water level, maximum water surface area, and full storage volume (dashed lines) as well as those identified by dead water level and dead storage volume (dotted lines). The cyan diamonds reported in panels (a) and (d) correspond to observations of water level and surface area obtained from from altimetry data and Landsat imagery.

affect our study, since those five reservoirs account for a small fraction of the total system's storage $(2.36 \%, 0.74 \%, 1.55 \%$, $0.69 \%$, and $0.64 \%$, respectively).

\subsection{Water Surface Area}

Recall that the WSA estimation algorithm builds on the idea of using cloudless images to create the expanded mask and zone mask, which are then employed to correct the classification of water pixels in images affected by clouds and other disturbances. 
In our case, such improvement is needed for $56 \%$ of the 3,004 Landsat images available for our study period (number of usable images increases from $26 \%$ to $82 \%$ ). As one might imagine, the classification correction is particularly important during the wet season, when cloud cover is more frequent-number of usable images increases by $54 \%$ of 1,770 images (from $30 \%$ to $84 \%$ ) in the dry season and $58 \%$ of 1,234 images (from $21 \%$ to $79 \%$ ) in the wet season. The performance of the algorithm for each reservoir is summarized in Table S5.

The WSA time series of Nuozhadu and Xiaowan reservoirs are reported in Figure 8. The first result to note is the stark change in the WSA values before (light blue points) and after (cyan points) the classification improvement. The time series of corrected WSA values also starts to reveal the reservoirs' operating patterns: the sharp increase beginning in 2012 (Nuozhadu) and 2009 (Xiaowan) denotes the starting point of the reservoir filling period, while the large, annual, fluctuations suggest the presence of a broad range of operating conditions - the maximum surface area is reached only at the end of the wet season, while the rest of year seems to be used to fill in and empty the reservoirs. In Section 4.3, we will see how such variability translates into storage patterns.
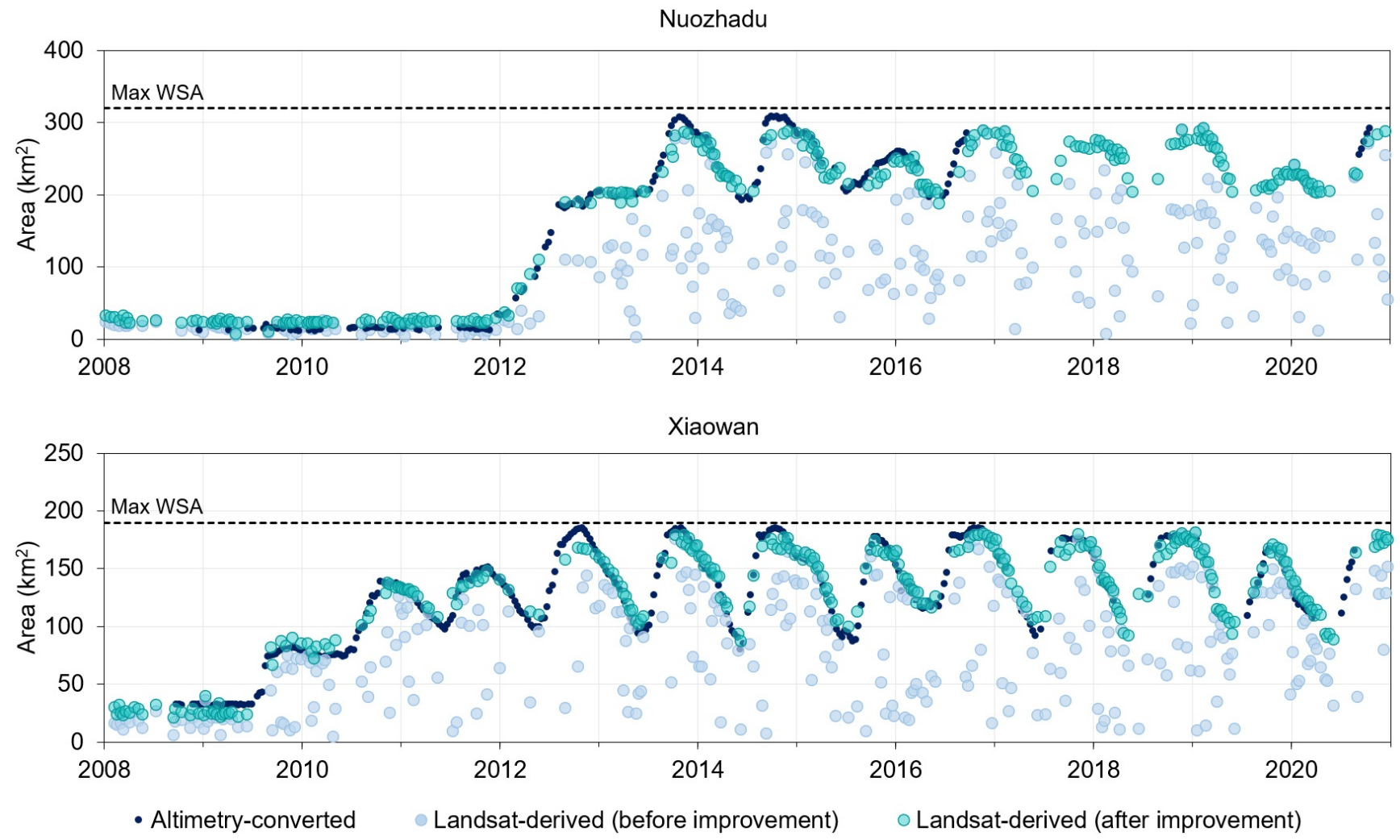

Figure 8. Water surface area of Nuozhadu (top) and Xiaowan (bottom) reservoirs. Note the drastic difference in WSA values before (light blue points) and after (cyan points) the classification improvement. The corrected values of WSA are well in agreement with those obtained through altimetry data and E-A curves (dark blue points). 
To evaluate the results obtained with Landsat imagery, we leverage the radar altimetry data from Jason 2 and 3 and EA curves to obtain two independent WSA time series-for Nouzhadu and Xiaowan. As shown in Figure 8, both modelling approaches provide very similar results. With this additional analysis we therefore serve two purposes: scrutinize the WSA values for the two main reservoirs and empirically validate the approach based on Landsat imagery, the only one available for the remaining reservoirs.

\subsection{Reservoir Storage}

\subsubsection{A history of reservoir storage variations}

Using the information on reservoir curves and water surface area described above, we estimate the storage time series of each reservoir as well as their aggregated value (Figure 9). Note that the number of usable images per month is not the same. To have an evenly spaced time series of storage, we choose one WSA value (maximum value) for each month to infer the reservoir storage. The latter (dark blue line) portrays a history of rapid transitions, characterized by two major tipping points: the commission of Xiaowan and Nuozhadu reservoirs. After the commission of Xiaowan, we note a steady increase in the total storage (see the period between mid 2009 to 2012); an increase that becomes even more pronounced after the commission of Nuozhadu, in 2012. It is indeed only after the filling of both reservoirs is completed, in 2014, that the total storage time series begins to exhibit a more cyclo-stationary behaviour-the reservoir system is filled during the monsoon season and emptied thereafter. The construction of a few additional dams during the period 2016-2018 does not seem to dramatically affect this pattern. In fact, the remaining eight reservoirs appear to maintain a more constant storage (Figure S4).

Two key additional elements are revealed when comparing the total storage dynamics against its potential range of variability, that is, the space between the aggregated dead and full storage (blue shaded area). First, the operators do not seem to use the entire storage at their disposal— dead and full storage levels were never reached throughout the study period. A plausible explanation for this management strategy may be sought in the need of avoiding further disputes with downstream countries (Eyler and Weatherby, 2020) or alleviating hydropower curtailment (Liu et al., 2018). Second, the reservoir system was used at only half of its capacity in 2015-2016 and 2019-2020, with Nuozhadu reservoir playing a key role (yellow line). As we shall see in Section 4.4, this may be the result of persistent dry conditions (Yu et al., 2020; Ding and Gao, 2020), rather than a response to the aforementioned socio-technical drivers.

\subsubsection{Filling strategies and operating rules}

325 Determining the filling strategy of a reservoir means deciding the rate with which the reservoir is filled and, therefore, the fraction of inflow that is retained on a periodic basis—monthly, in our case. The problem is formalized by the following mass balance equation:

$S_{t}=S_{t-1}+\theta \cdot Q_{t}-E_{t}$, 


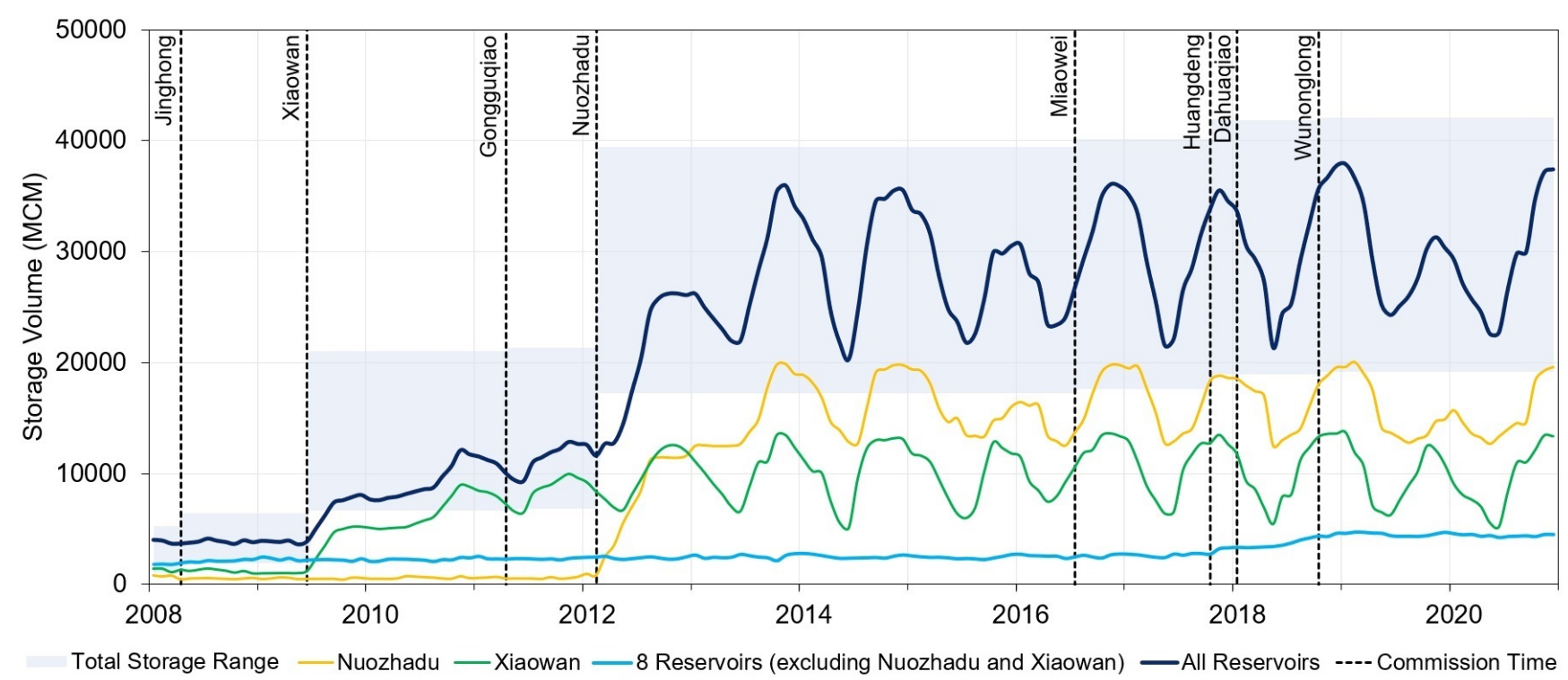

Figure 9. The blue shaded area represents the range of variability of the total system's storage (between dead and full storage volume), while the actual storage dynamics are represented by the dark blue line. The storage dynamics of Nuozhadu, Xiaowan, and the remaining eight reservoirs are illustrated by the yellow, green, and blue lines. The vertical dashed lines denote the year of commission of each reservoir. Note that Manwan and Dachaoshan began operations in 1992 and 2003, respectively. We provide the storage time series of each individual reservoir in Figure S4.

where $S_{t}$ is the reservoir storage at time $t, Q_{t}$ the inflow volume in the interval $(t-1, t], E_{t}$ the evaporation loss in the interval $(t-1, t]$, and $\theta$ a parameter varying between 0 and 1 and expressing the fraction of inflow volume retained by the reservoir. In our case, the goal is to determine the value of $\theta$ (in each month) for Nuozhadu and Xiaowan. To this purpose, we use the storage data described above and calculate the evaporation loss using the estimated water surface area and monthly evaporation rates. Observed inflow data are not available, so we resort to modelled ones. Specifically, we use daily inflow data simulated by VIC-Res, a large-scale, semi-distributed model that simulates not only hydrological processes (evapotranspiration, infiltration, baseflow, and runoff) but also the streamflow routing and storage dynamics of each reservoir (Dang et al., 2020b). VIC-Res has been tested on several sites, including the Lancang River Basin (Dang et al., 2020a). With the time series of $S, Q$, and $E$ at hand, we proceed to study the filling strategy of the two reservoirs.

In Figure 10, panels $(\mathrm{a}, \mathrm{b})$ show the values of $\theta$, while panels $(\mathrm{c}, \mathrm{d})$ illustrate storage volume (dark blue line), simulated inflow (green line), and storage change (light blue line)— that is, $S_{t}-S_{t-1}$, expressing the rate with which the reservoir is filled. The figure suggests that the operators adopted similar filling strategies: both reservoirs were filled in about two years (regardless of the different capacities), with the first wet season used to meet the dead storage and the second wet season used to double the storage volume. Interestingly, results indicate that the annual value of $\theta$ was kept constant during the filling period. For Nuozhadu, the operators retained $23 \%$ of the annual inflow volume (for both years); for Xiaowan, that value was kept to $17 \%$ 
Nuozhadu
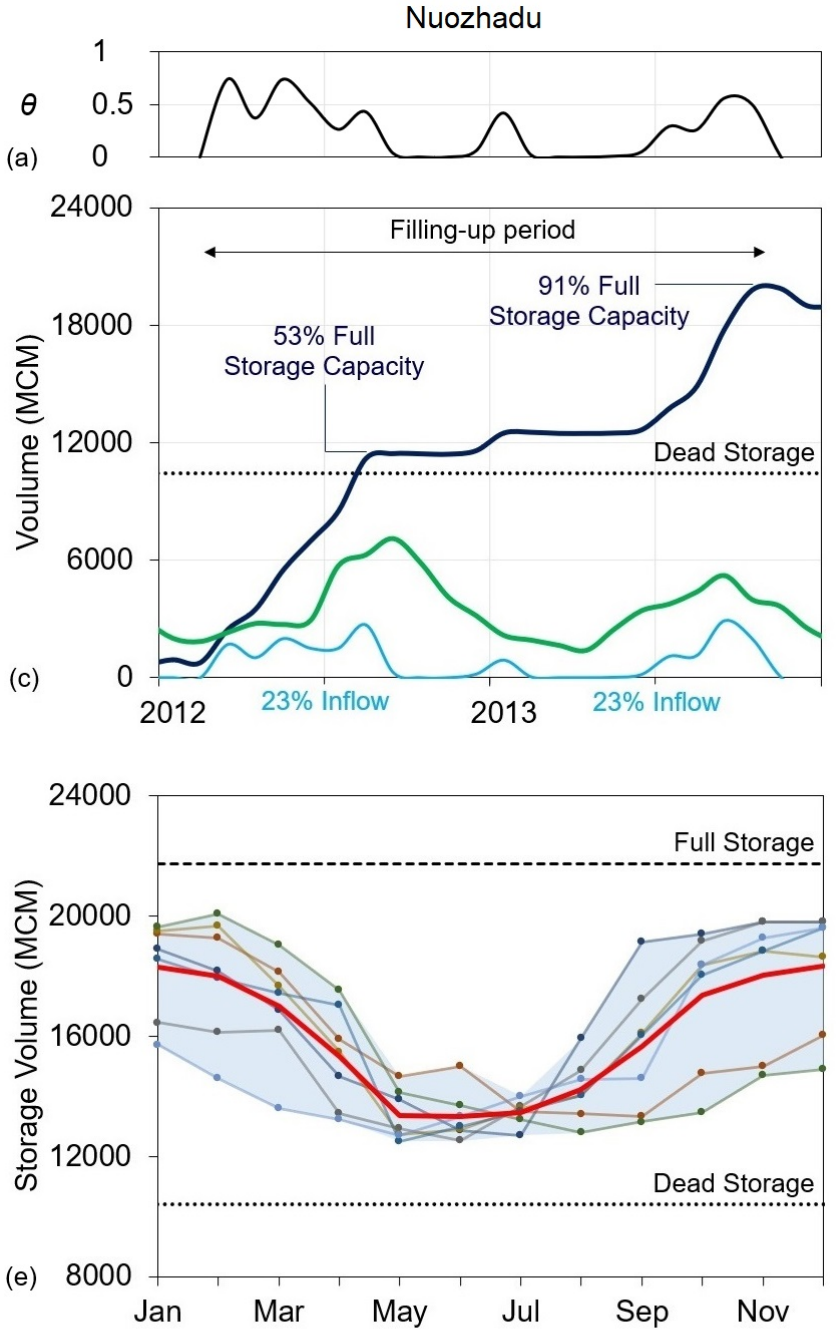

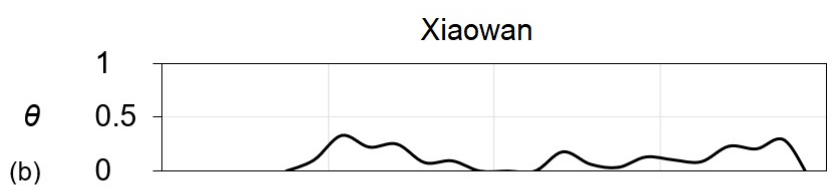

(b)

(d)
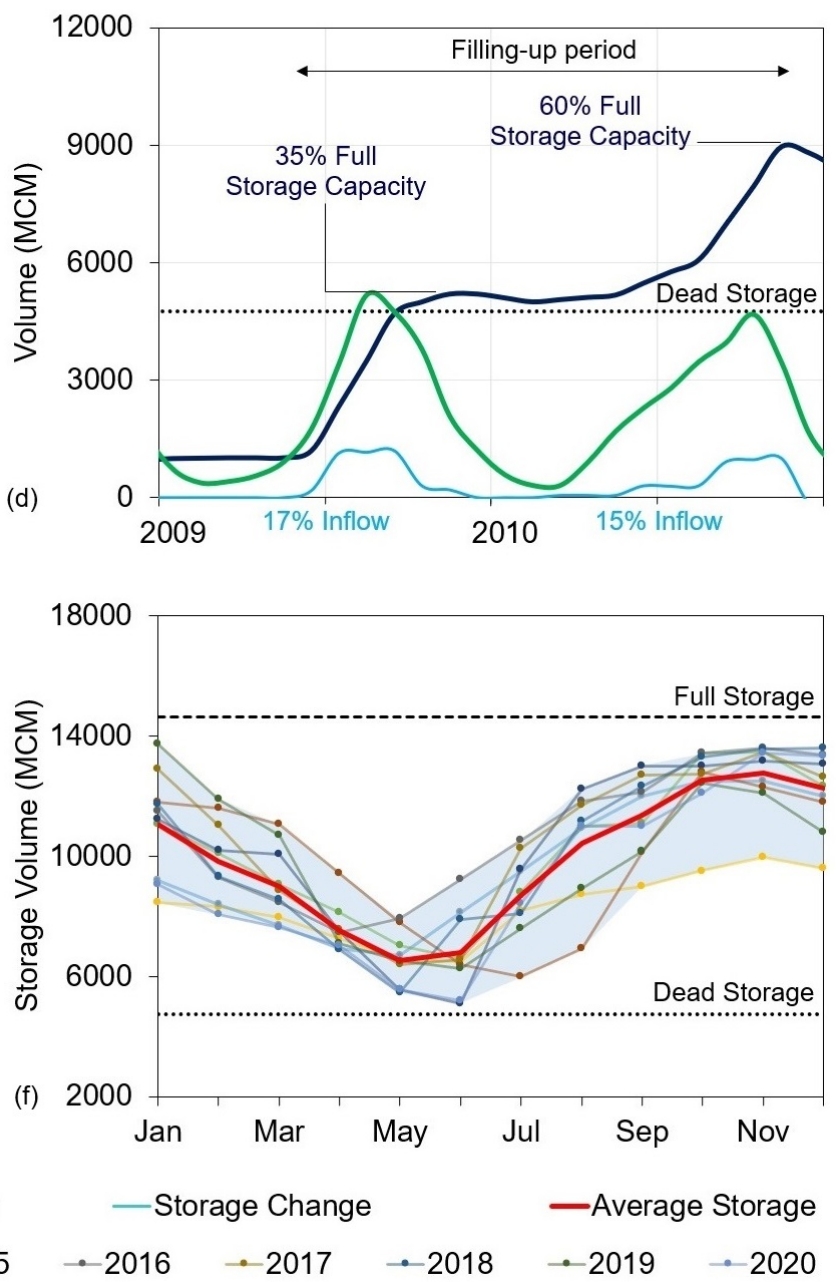

Figure 10. Filling strategies (a,b,c,d) and rule curves (e,f) of Nuozhadu (left) and Xiaowan (right) reservoirs. Panels (a,b) show the values of $\theta$. In panels (c,d), the storage volume (dark blue line) is derived from DEM and Landsat data, while the inflow to the reservoir (green line) is calculated with the VIC-Res hydrological model (see Figure S5 for additional details). The storage change (light blue line) is defined as the difference in storage volume between two consecutive months. In panels (e,f), each line with circle makers illustrates the storage volume of a given year. The red bolded lines represent the average monthly storage volume, considered representative of the rule curves. All data visualized here have a monthly resolution.

and $15 \%$. Note that these are extremely large values: retaining $23 \%$ of the annual inflow volume to Nuozhadu means storing 
roughly $9880 \mathrm{Mm}^{3}, \sim 12 \%$ of the average annual discharge at Chiang Saen. The filling strategy of the remaining reservoirs is different: because they have smaller storage capacity—relative to inflow—they are filled in a few months (see Figure S4).

By looking at the storage data of Nuozhadu and Xiaowan during normal operating conditions (i.e., once the filling is completed), we can get a few additional insights about the current management strategies (Figure $10(\mathrm{e}, \mathrm{f})$ ). The first thing to note is the emergence of the seasonal patterns mentioned in the previous section; reservoirs are emptied during the pre-monsoon season and filled in thereafter. Second, the envelope of variability is rather broad, meaning that operators can deviate from the long-term pattern represented by the red bolded line. Such deviations are common throughout the entire Mekong Basin (see Bonnema and Hossain $(2017,2019)$ ) and are caused by inter-annual variability in discharge triggered by oceanic drivers (Nguyen et al., 2020). Finally, the analysis confirms that Nuozhadu and Xiaowan have not yet been used at their full capacity. However, this is is enough to keep the storage of the other reservoirs within a narrower range (Figure S6).

\subsection{Impacts of Reservoir Operations on Downstream Discharge}

Having established how the reservoirs in the Lancang River Basin have been filled in and operated, we can finally explain their time-varying influence on the discharge measured at Chiang Saen (Section 2.1). The graphical analysis of total storage and discharge (Figure 11 (c)) highlights the stark changes in the flow regime in response to the increase in upstream storage. The flow regime changed drastically in late 2013, when the filling of Xiaowan and Nuozhadu was completed. By discharging water during the dry season and retaining it in the wet season, the hydropower dams largely increase low flows and decrease high flows (Table S6). For example, the mean of the annual peak discharge decreased from 11,157 (1990-2008) to 6,186 $\mathrm{m}^{3} / \mathrm{s}$ (2013-2020) (-45\%), while the mean of the annual lowest discharge grew from 638 to $1,003 \mathrm{~m}^{3} / \mathrm{s}(+57 \%)$. Similar figures are found for other statistics (Table S6). We can also note a macroscopic change in the seasonal discharge pattern, from ample annual fluctuations to more rapid flow changes. All these observations are confirmed by the wavelet analysis reported in Figure S7.

The availability of storage data also allows us to decipher the impact of dam operations on downstream discharge. To do that, we calculate the following time-varying indicator of hydrological alteration:

$I_{t}=\frac{\Delta S_{t}}{\Delta S_{t}+Q_{t}}$

where $\Delta S_{t}$ is the storage change (i.e., $S_{t}-S_{t-1}$ ) and $Q_{t}$ the observed discharge at Chiang Saen. The denominator approximates

the natural flow (it is the sum of actual discharge and volume of water retained upstream in a given interval), so the indicator $I_{t}$ tells us what fraction of the natural flow is actively controlled by the Lancang dams in a given time interval (one month). Positive values of $I_{t}$ indicate that the reservoir system is storing water and negative values that the system is releasing it. As shown in Figure 11 (b), the degree of flow alteration caused by the Lancang's dams increased significantly over time with three distinct stages: the first stage (before Xiaowan reservoir began operating), the middle stage, and last stage (after Nuozhadu reservoir began operating). That means the range of variability of $I_{t}$ increased over time; -0.11 to 0.04 in the first stage, -0.33 to 0.2 in the second stage, and -0.83 to 0.5 in the last stage. With the number of reservoirs increasing rapidly in the last decade, the downstream discharge became increasingly dependent on dam operations. 


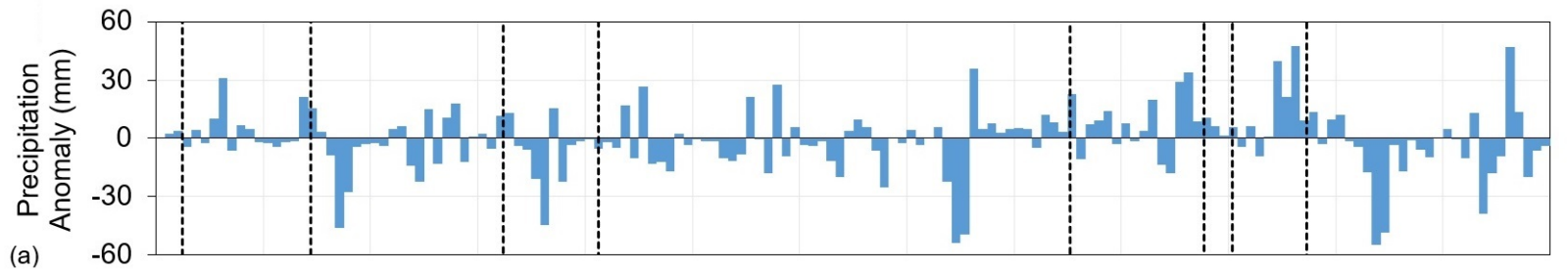

(a)

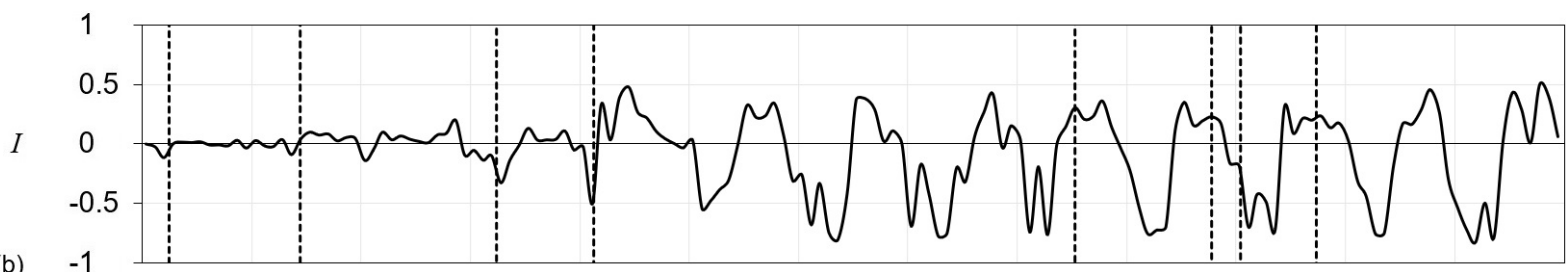

(b)

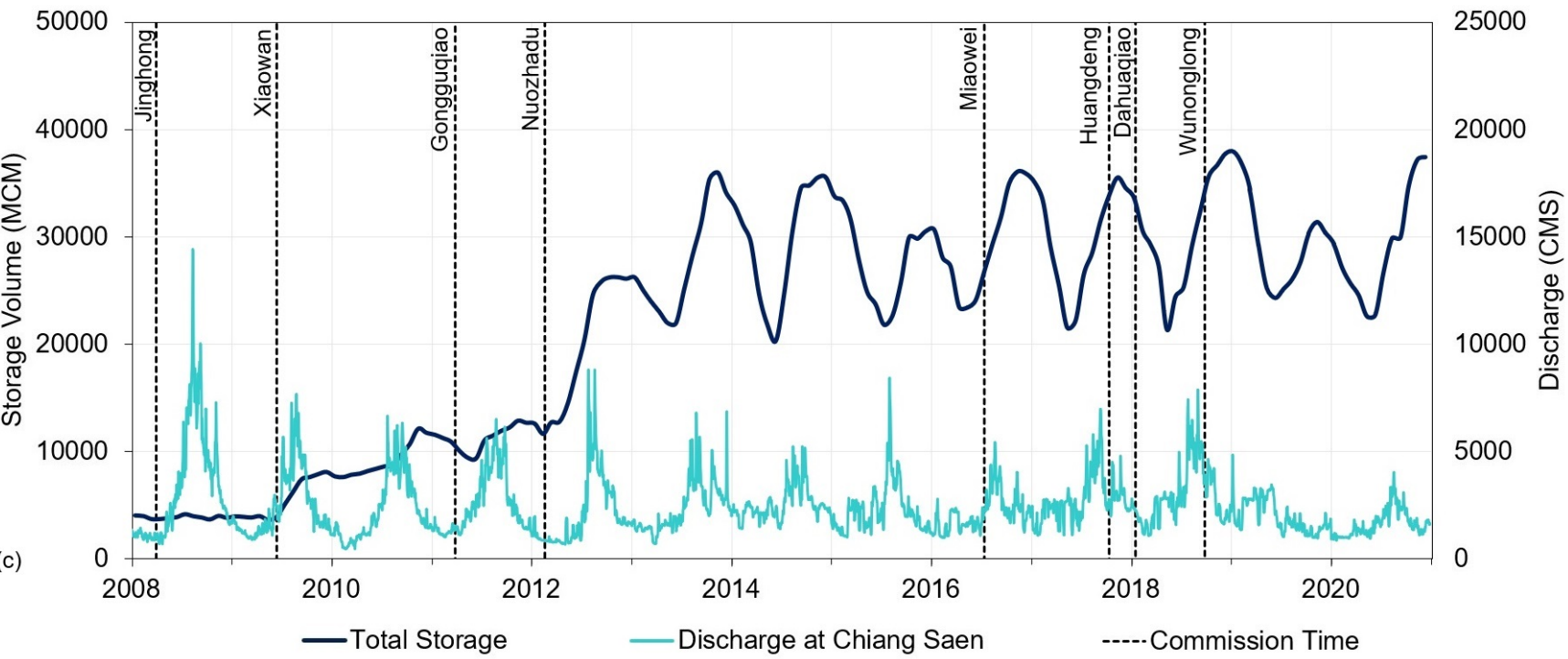

Figure 11. Impacts of reservoir operations on downstream discharge. Panel (a) shows the monthly precipitation anomaly in the Lancang River Basin, calculated from the CHIRPS-2.0 dataset. Panel (b) represents the ratio between two variables: the change in storage volume in the reservoir system $(\Delta \mathrm{S})$, and the sum of discharge volume at Chiang Saen and change in storage volume in the reservoir system $(\mathrm{Q}+\Delta \mathrm{S})$. Positive values indicate that the reservoir system is storing water, while negative values indicate that water is being discharged. In panel (c), the bolded dark blue line represents the total storage of the reservoir system, while the cyan line represents the observed discharge at Chiang Saen.

By bringing the monthly precipitation anomalies (for the Lancang River Basin) into the overall picture (Figure 11 (a)), we can better understand how dam operations contributed to downstream droughts and pluvials. A case in point is the drought in the period 2019-2020. The monthly precipitation anomalies show that, in the wet season of 2019, the Lancang River Basin received less precipitation, especially in May and June (around $50 \mathrm{~mm}$ less than the average for those months). However, the values of $I_{t}$ during this period indicate that the reservoir system kept retaining the inflow (up to about $46 \%$ in October). As a 
result, the downstream area underwent a critical dry period, with Chiang Saen gauging station recording extremely low flows during the wet season (MRC, 2020a). The release of water during the subsequent dry season only partially alleviated the effect of the ongoing drought, since the low precipitation period persisted until mid-2020. Importantly, the 2019-2020 data suggest that the dam operating strategy is not largely affected by the meteorological conditions: the Lancang dams currently store about $46 \%$ of the estimated natural flow during the wet season (regardless of the monsoon's intensity) and then discharge it during the dry one, controlling up to $83 \%$ of the dry season flow — a pattern that emerged since Xiaowan and Nuozhadu became fully operational.

\section{Discussion}

Our study produced a monthly storage time series for each of the ten large reservoirs built in the Lancang River Basin during the past decades. These time series describe the evolution of a massive dam cascade system and highlight the pivotal role played by Xiaowan and Nuozhadu reservoirs. Taken together, the two reservoirs can make up to $\sim 85 \%$ of the total system's storage in the Lancang, therefore largely controlling water availability in Northern Thailand and Laos. Bespoke information on their operating rules_ideally combined with real-time storage monitoring - is of paramount importance for many downstream socio-economic sectors. Consider, for instance, the Laotian hydropower industry, the largest regional exporter of electricity: since the construction of Xayaburi dam (1285 MW) on the main stem of the Mekong, part of the national hydropower production depends on the state of the Lancang's reservoirs. Detailed information on their storage and operating rules could therefore be incorporated into Laos' energy system models (Chowdhury et al., 2020), so as to address the asymmetric relation between China and Laos. Moving downstream, another sector that could benefit of our study are the Mekong's wetlands, a major biodiversity hotspot that is home to a multi-billion dollar fishing industry (Arias et al., 2014; Dang et al., 2016). Again, information on the state of the Lancang's reservoirs could help inform the operations of the many downstream dams, thereby helping implement release strategies that are less harmful for the environment (Sabo et al., 2017). In sum, the inferred rule curves could be used to predict outflow from the Lancang's reservoir system and adapt the operations of downstream dams.

Our analysis also provides a detailed description of the filling strategy of Nuozhadu and Xiaowan. We now know that both reservoirs reached steady-state operations in about two years by retaining from $15 \%$ to $23 \%$ of the annual inflow volume. This information is necessary to explain past anomalies in downstream water discharge and, most important, to prepare for future infrastructural changes in the Lancang's dam cascade system. China is already building a new dam (Tuoba; $1039 \mathrm{Mm}^{3}$ ) and planning the construction of ten additional ones (MRC, 2020b). If the same filling strategies were to be implemented again, downstream countries should expect a temporary, yet substantial, decrease of water availability, but could also design adaptation and emergency plans. For example, Laos or Cambodia could decide to temporarily change their water management strategies when a new dam becomes operational in the Lancang. Naturally, information on the past filling strategies could also be used when negotiating the filling of new dams - as for the case of the Grand Ethiopian Renaissance Dam (Zhang et al., 2016; Basheer et al., 2020) — a more desirable and cooperative policy that does not seem to appear at the horizon. 

based on 'static' indicators that relate the storage capacity to the average annual discharge volume (Grill et al., 2014, 2015). By coupling actual storage time series with discharge data we can go beyond this first, fundamental, characterization and provide a gateway for a more nuanced understanding of how, and when, reservoir operations affect downstream hydrological processes (Bonnema and Hossain, 2017). In that regard, our results for the Lancang indicate that the fraction of natural flow actively controlled by dams (in northern Thailand and Laos) changes on a monthly basis: reservoirs hold up to $\sim 50 \%$ of the natural flow during the wet season and control almost $83 \%$ of the dry season flow coming out of Lancang. Interestingly, we also found that this periodic pattern is not much affected by the hydro-meteorological conditions—-like the 2019 drought—partially explaining the complaints and fears of the downstream countries (Eyler and Weatherby, 2020).

From a more technical perspective, another research area that might be influenced by our results is the development of largescale hydrological models for the Mekong basin. Hydrologists are indeed increasingly interested in the representation of water reservoir storage and operations, a modelling problem that has long lasted on generic reservoir release schemes (Hanasaki et al., 2006). Recent research has shown that the nuances of operations at individual dams are better captured by hydrological models when building on high-resolution data available for each dam (Turner et al., 2020). In this regard, we believe our storage and water level time series provide an opportunity for testing and improving the many hydrological models developed for the Mekong basin (Hoang et al., 2019; Yu et al., 2019; Dang et al., 2020a; Yun et al., 2020; Shin et al., 2020; Do et al., 2020). A complementary research direction is the creation of additional datasets for other key variables, such as water temperature or suspended sediment concentrations, which can also be observed, or inferred, from satellite observations (Beveridge et al., 2020; Bonnema et al., 2020).

Looking forward, we should aim at repeating studies like this one at the scale of the entire river basin. Doing that would create a pathway to a robust attribution analysis of the recent droughts that affected the Mekong countries. It should be noted that such analysis is probably not yet within our reach: we know how runoff generation is spatially distributed (Shin et al., 2020) and we are gathering information on the operations of many reservoirs (Biswas et al., 2021), but we still have limited data on other anthropogenic interventions that arguably affect the overall water balance, such as irrigation activities in the western part of the basin. In turn, this reiterate the need for high-resolution data spanning across countries and socio-economic sectors.

\section{Conclusions}

In just a few decades, the Mekong River basin has undergone a rapid infrastructure development that has fostered economic growth, but also damaged the environment and challenged the relation between riparian countries. A change in this status quo means conceiving cooperative water-energy policies that span across countries and socio-economic sectors (Schmitt et al., 2019; Siala et al., 2021). Aside from the political will, an important piece of the puzzle is the availability of open source datasets that describe how big infrastructures have been operated. Since agreements on data sharing only provide piecemeal information (Johnson, 2020), the use of satellite imagery appears to be the only way to create unbiased observations available to research 
https://doi.org/10.5194/hess-2021-360

Preprint. Discussion started: 5 August 2021

(c) Author(s) 2021. CC BY 4.0 License.

community and local stakeholders. In this regard, our work complements the existing efforts for the region, bringing us one step closer to a complete understanding of China's management strategies for the Lancang's dams. Importantly, the lessons learnt here could be readily applied to other transboundary river basins, where the lack of information on existing and planned dams is a major obstacle to open science and institutionalized cooperation.

Author contributions. D.T.V., T.D.D., and S.G. conceptualized the paper and its scope. Data collection and all analyses were carried out by D.T.V. S.G. and D.T.V wrote the manuscript, with substantial inputs from all authors.

Code and data availability. The Python scripts used in this study and the corresponding output (E-A-S curves and storage time series) are available at https://github.com/dtvu2205/210520. The daily discharge data at Chiang Saen were collected from the Mekong River Commission web portal, https://portal.mrcmekong.org/. CHIRPS-2.0 precipitation data from University of California, Santa Barbara, are available at https://data.chc.ucsb.edu/products/CHIRPS-2.0/. The SRTM-DEM is available at https://earthexplorer.usgs.gov/. All Landsat images used in our study are available at https://earthexplorer.usgs.gov/. The altimetry data are retrieved from the Global Reservoirs and Lakes Monitor (G-REALM), https://ipad.fas.usda.gov/cropexplorer/global_reservoir/.

Acknowledgements. Dung Trung Vu is supported by the SUTD PhD Fellowship. Thanh Duc Dang and Stefano Galelli are supported by Singapore's Ministry of Education (MoE) through the Tier 2 project 'Linking water availability to hydropower supply-an engineering systems approach' (Award No. MOE2017-T2-1-143). 


\section{References}

Arias, M. E., Cochrane, T. A., Kummu, M., Lauri, H., Holtgrieve, G. W., Koponen, J., and Piman, T.: Impacts of hydropower and climate change on drivers of ecological productivity of Southeast Asia's most important wetland, Ecological Modelling, 272, 252-263, https://doi.org/10.1016/j.ecolmodel.2013.10.015, 2014.

Avisse, N., Tilmant, A., Müller, M. F., and Zhang, H.: Monitoring small reservoirs' storage with satellite remote sensing in inaccessible areas, Hydrology and Earth System Sciences, 21, 6445-6459, https://doi.org/10.5194/hess-21-6445-2017, 2017.

Basheer, M., Wheeler, K. G., Elagib, N. A., Etichia, M., Zagona, E. A., Abdo, G. M., and Harou, J. J.: Filling Africa's largest hydropower dam should consider engineering realities, One Earth, 3, 277-281, https://doi.org/10.1016/j.oneear.2020.08.015, 2020.

Beveridge, C., Hossain, F., and Bonnema, M.: Estimating impacts of dam development and landscape changes on suspended sediment concentrations in the Mekong River Basin's 3S tributaries, Journal of Hydrologic Engineering, 25, 05020014, https://doi.org/10.1061/(asce)he.1943-5584.0001949, 2020.

Binh, D. V., Kantoush, S., and Sumi, T.: Changes to long-term discharge and sediment loads in the Vietnamese Mekong Delta caused by upstream dams, Geomorphology, 353, 107 011, https://doi.org/10.1016/j.geomorph.2019.107011, 2020.

Biswas, N. K., Hossain, F., Bonnema, M., Okeowo, M. A., and Lee, H.: An altimeter height extraction technique for dynamically changing rivers of South and South-East Asia, Remote Sensing of Environment, 221, 24-37, https://doi.org/10.1016/j.rse.2018.10.033, 2019.

Biswas, N. K., Hossain, F., Bonnema, M., Lee, H., and Chishtie, F.: Towards a global Reservoir Assessment Tool for predicting hydrologic impacts and operating patterns of existing and planned reservoirs, Environmental Modelling and Software, 140, 105043, https://doi.org/10.1016/j.envsoft.2021.105043, 2021.

Bonnema, M. and Hossain, F.: Inferring reservoir operating patterns across the Mekong Basin using only space observations, Water Resources Research, 53, 3791-3810, https://doi.org/10.1002/2016wr019978, 2017.

Bonnema, M. and Hossain, F.: Assessing the potential of the Surface Water and Ocean Topography mission for reservoir monitoring in the Mekong River Basin, Water Resources Research, 55, 444-461, https://doi.org/10.1029/2018wr023743, 2019.

Bonnema, M., Sikder, S., Miao, Y., Chen, X., Hossain, F., Pervin, I. A., Rahman, S. M. M., and Lee, H.: Understanding satellite-based monthly-to-seasonal reservoir outflow estimation as a function of hydrologic controls, Water Resources Research, 52, 4095-4115, https://doi.org/10.1002/2015wr017830, 2016.

Bonnema, M., Hossain, F., Nijssen, B., and Holtgrieve, G.: Hydropower's hidden transformation of rivers in the Mekong, Environmental Research Letters, 15, 044 017, https://doi.org/10.1088/1748-9326/ab763d, 2020.

Busker, T., de Roo, A., Gelati, E., Schwatke, C., Adamovic, M., Bisselink, B., Pekel, J.-F., , and Cottam, A.: A global lake and reservoir volume analysis using a surface water dataset and satellite altimetry, Hydrology and Earth System Sciences, 23, 669-690, https://doi.org/10.5194/hess-23-669-2019, 2019.

Chowdhury, A. K., Dang, T. D., Bagchi, A., and Galelli, S.: Expected benefits of Laos' hydropower development curbed by hydro-climatic variability and limited transmission capacity: opportunities to reform, Journal of Water Resources Planning and Management, 146, 05020 019, https://doi.org/10.1061/(asce)wr.1943-5452.0001279, 2020.

Chowdhury, A. K., Dang, T. D., Nguyen, H. T. T., Koh, R., and Galelli, S.: The Greater Mekong's climate-water-energy nexus: How ENSO-triggered regional droughts affect power supply and $\mathrm{CO}_{2}$ emissions, Earth's Future, 9, e2020ef001814, https://doi.org/10.1029/2020ef001814, 2021. 

in the Mekong floodplains, Hydrological Processes, 30, 3824-3838, https://doi.org/10.1002/hyp.10894, 2016.

Dang, T. D., Chowdhury, A. K., and Galelli, S.: On the representation of water reservoir storage and operations in large-scale hydrological models: Implications on model parameterization and climate change impact assessments, Hydrology and Earth System Sciences, 24, 397-416, https://doi.org/10.5194/hess-24-397-2020, 2020a.

Dang, T. D., Vu, D. T., Chowdhury, A. K., and Galelli, S.: A software package for the representation and optimization of water reservoir operations in the VIC hydrologic model, Environmental Modelling \& Software, 126, 104 673, https://doi.org/10.1016/j.envsoft.2020.104673, $2020 \mathrm{~b}$.

Didan, K. and Munoz, A. B.: MODIS vegetation index user's guide (MOD13 Series), Vegetation Index and Phenology Lab, The University of Arizona, https://vip.arizona.edu/documents/MODIS/MODIS_VI_UsersGuide_09_18_2019_C61.pdf, accessed 20 May 2021 , 2019.

Ding, T. and Gao, H.: The record-breaking extreme drought in Yunnan Province, Southwest China during spring-early summer of 2019 and possible causes, Journal of Meteorological Research, 34, 997-1012, https://doi.org/10.1007/s13351-020-0032-8, 2020.

Do, P., Tian, F., Zhu, T., Zohidov, B., Ni, G., Lu, H., and Liu, H.: Exploring synergies in the water-food-energy nexus by using an integrated hydro-economic optimization model for the Lancang-Mekong River Basin, Science of The Total Environment, 728, 137996, https://doi.org/10.1016/j.scitotenv.2020.137996, 2020.

515 Duan, Z. and Bastiaanssen, W. G. M.: Estimating water volume variations in lakes and reservoirs from four operational satellite altimetry databases and satellite imagery data, Remote Sensing of Environment, 134, 403-416, https://doi.org/10.1016/j.rse.2013.03.010, 2013.

Eyler, B. and Weatherby, C.: New evidence: How China turned off the tap on the Mekong River, The Stimson Center, https://www.stimson. org/2020/new-evidence-how-china-turned-off-the-mekong-tap/, accessed 20 May 2021, 2020.

Eyler, B., Basist, A., Carr, A., and Williams, C.: Mekong dam MZonitor: Methods and Processes, The Stimson Center, https://www.stimson. org/2020/mekong-dam-monitor-methods-and-processes/, accessed 20 May 2021, 2020.

Gao, H.: Satellite remote sensing of large lakes and reservoirs: From elevation and area to storage, Wiley Interdisciplinary Reviews: Water, 2, 145-157, https://doi.org/10.1002/wat2.1065, 2015.

Gao, H., Birkett, C., and Lettenmaier, D. P.: Global monitoring of large reservoir storage from satellite remote sensing, Water Resources Research, 48, w09 504, https://doi.org/10.1029/2012wr012063, 2012.

Grill, G., Dallaire, C. O., Chouinard, E. F., Sindorf, N., and Lehnera, B.: Development of new indicators to evaluate river fragmentation and flow regulation at large scales: A case study for the Mekong River Basin, Ecological Indicators, 45, 148-159, https://doi.org/10.1016/j.ecolind.2014.03.026, 2014.

Grill, G., Lehner, B., Lumsdon, A. E., GrahamKMacDonald, Zarfl, C., and Liermann, C. R.: An index-based framework for assessing patterns and trends in river fragmentation and flow regulation by global dams at multiple scales, Environmental Research Letter, 10, 145-157, https://doi.org/10.1088/1748-9326/10/1/015001, 2015.

Hanasaki, N., Kanae, S., and Oki, T.: A reservoir operation scheme for global river routing models, Journal of Hydrology, 327, 22-41, https://doi.org/10.1016/j.jhydrol.2005.11.011, 2006.

Hecht, J. S., Lacombe, G., Arias, M. E., Dang, T. D., and Piman, T.: Hydropower dams of the Mekong River Basin: A review of their hydrological impacts, Journal of Hydrology, 568, 285-300, https://doi.org/10.1016/j.jhydrol.2018.10.045, 2019.

Hoang, L. P., van Vliet, M. T. H., Kummu, M., Lauri, H., Koponen, J., Supit, I., Leemans, R., Kabat, P., and Ludwiga, F.: The Mekong's future flows under multiple drivers: How climate change, hydropower developments and irrigation expansions drive hydrological changes, Science of the Total Environment, 649, 601-609, https://doi.org/10.1016/j.scitotenv.2018.08.160, 2019. 
IRN: China's Upper Mekong dams endanger millions downstream, International Rivers Network, https://www.irn.org/files/pdf/mekong/ MekongFactSheet2002.pdf, accessed 20 May 2021, 2002.

Johnson, K.: China commits to share year-round water data with Mekong River Commission, Reuters, https://www.reuters.com/article/ us-mekong-river/china-commits-to-share-year-round-water-data-with-mekong-river-commission-idINKBN277135, accessed 20 May $2021,2020$.

Kallio, M. and Fallon, A.: Critical Nature: Are China's dams on the Mekong causing downstream drought? The importance of scientific debate, The Center for Social Development Studies, https://www.csds-chula.org/publications/2020/4/28/ critical-nature-are-chinas-dams-on-the-mekong-causing-downstream-drought-the-importance-of-scientific-debate, accessed 20 May $2021,2020$.

Kattelus, M., Kummu, M., Keskinen, M., Salmivaara, A., and Varis, O.: China's southbound transboundary river basins: A case of asymmetry, Water International, 40, 113-138, 2015.

Kondolf, G. M., Schmitt, R. J. P., Carling, P., Darby, S., Arias, M., Bizzi, S., Castelletti, A., Cochrane, T. A., Gibson, S., Kummu, M., Oeurng, C., Rubin, Z., and Wild, T.: Changing sediment budget of the Mekong: Cumulative threats and management strategies for a large river basin, Science of The Total Environment, 625, 114-134, https://doi.org/10.1016/j.scitotenv.2017.11.361, 2018.

Li, Y., Gao, H., Jasinski, M. F., Zhang, S., and Stoll, J. D.: Deriving high-resolution reservoir bathymetry from ICESat-2 prototype photon-counting lidar and Landsat imagery, IEEE Transactions on Geoscience and Remote Sensing, 57, 7883-7893, https://doi.org/10.1109/tgrs.2019.2917012, 2019.

Liu, B., Liao, S., Cheng, C., Chen, F., and Li, W.: Hydropower curtailment in Yunnan Province, southwestern China: Constraint analysis and suggestions, Renewable Energy, 121, 700-711, https://doi.org/10.1016/j.renene.2018.01.090, 2018.

Liu, K.-T., Tseng, K.-H., Shum, C. K., Liu, C.-Y., Kuo, C.-Y., Liu, G., Jia, Y., and Shang, K.: Assessment of the impact of reservoirs in the Upper Mekong River using satellite radar altimetry and remote sensing imageries, Remote Sensing, 8, 367, https://doi.org/10.3390/rs8050367, 2016.

560 MRC: The flow of the Mekong, Vientiane: Mekong River Commission Secretariat, 2009.

MRC: Understanding the Mekong River's hydrological conditions: A brief commentary note on the "Monitoring the quantity of water flowing through the Upper Mekong Basin under natural (unimpeded) conditions" study by Alan Basist and Claude Williams (2020), Vientiane: Mekong River Commission Secretariat, 2020a.

MRC: Sub-basins, major rivers and evaluation of the UMB in China, Mekong River Commission, https://www.mrcmekong.org/our-work/ topics/hydropower/, accessed 20 May 2021, 2020b.

Nguyen, H. T. T., Turner, S. W., Buckley, B. M., and Galelli, S.: Coherent streamflow variability in Monsoon Asia over the past eight centuries-links to oceanic drivers, Water Resources Research, 56, e2020wr027 883, https://doi.org/10.1029/2020wr027883, 2020.

Pekel, J.-F., Cottam, A., Gorelick, N., and Belward, A. S.: High-resolution mapping of global surface water and its long-term changes, Nature, 540, 418-422, https://doi.org/10.1038/nature20584, 2016.

570 Pickens, A. H., C.Hansen, M., Hancher, M., Stehman, S. V., Tyukavina, A., Potapov, P., Marroquin, B., and Sherani, Z.: Mapping and sampling to characterize global inland water dynamics from 1999 to 2018 with full Landsat time-series, Remote Sensing of Environment, 243, 111 792, https://doi.org/10.1016/j.rse.2020.111792, 2020.

Räsänen, T. A., Someth, P., Lauri, H., Koponen, J., Sarkkula, J., and Kummu, M.: Observed river discharge changes due to hydropower operations in the Upper Mekong Basin, Journal of Hydrology, 545, 28-41, https://doi.org/10.1016/j.jhydrol.2016.12.023, 2017. 

food security futures in the Lower Mekong Basin, Science, 358, eaao1053, https://doi.org/10.1126/science.aao1053, 2017.

Schmitt, R. J. P., Bizzi, S., Castelletti, A., Opperman, J. J., and Kondolf, G. M.: Planning dam portfolios for low sediment trapping shows limits for sustainable hydropower in the Mekong, Science Advances, 5, eaaw2175, https://doi.org/10.1126/sciadv.aaw2175, 2019.

Schwatke, C., Dettmering, D., Bosch, W., and Seitz, F.: DAHITI - an innovative approach for estimating water level time series over inland waters using multi-mission satellite altimetry, Hydrology and Earth System Sciences, 19, 4345-4364, https://doi.org/10.5194/hess-194345-2015, 2015.

Shin, S., Pokhrel, Y., Yamazaki, D., Huang, X., Torbick, N., Qi, J., Pattanakiat, S., Ngo-Duc, T., and Nguyen, T. D.: High resolution modeling of river-floodplain-reservoir inundation dynamics in the Mekong River Basin, Water Resources Research, 56, e2019wr026449, https://doi.org/10.1029/2019wr026449, 2020.

Siala, K., Chowdhury, A. K., Dang, T. D., and Galelli, S.: Solar energy and regional coordination as a feasible alternative to large hydropower in Southeast Asia, Nature Communications, https://doi.org/10.1038/s41467-021-24437-6, 2021.

Soukhaphon, A., Baird, I. G., and Hogan, Z. S.: The impacts of hydropower dams in the Mekong River Basin: A review, Water, 13, 256, https://doi.org/10.3390/w13030265, 2021.

Tortini, R., Noujdina, N., Yeo, S., Ricko, M., Birkett, C. M., Khandelwal, A., Kumar, V., Marlier, M. E., and Lettenmaier, D. P.: Satellitebased remote sensing data set of global surface water storage change from 1992 to 2018, Earth System Science Data, 12, 1141-1151, https://doi.org/10.5194/essd-12-1141-2020, 2020.

Turner, S. W. D., Doering, K., and Voisin, N.: Data-driven reservoir simulation in a large-scale hydrological and water resource model, Water Resources Research, 56, e2020WR027 902, https://doi.org/10.1029/2020wr027902, 2020.

Warner, J. and Zawahri, N.: Hegemony and asymmetry: Multiple-chessboard games on transboundary rivers, International Environmental Agreements: Politics, Law and Economics, 12, 215-229, 2012.

Wei, J., Wei, Y., Tian, F., Nott, N., de Witt, C., Guo, L., and Lu, Y.: News media coverage of conflict and cooperation dynamics of water events in the Lancang-Mekong River basin, Hydrology and Earth System Sciences, 25, 1603-1615, 2021.

Williams, J. M.: Is three a crowd? River basin institutions and the governance of the Mekong River, International Journal of Water Resources Development, https://doi.org/10.1080/07900627.2019.1700779, 2020.

Yu, Y., Zhao, J., Li, D., and Wang, Z.: Effects of hydrologic conditions and reservoir operation on transboundary cooperation in the LancangMekong River Basin, Journal of Water Resources Planning and Management, 145, 04019 020, https://doi.org/10.1061/(asce)wr.1943$5452.0001075,2019$.

Yu, Y., Wang, J., Cheng, F., Deng, H., and Chen, S.: Drought monitoring in Yunnan Province based on a TRMM precipitation product, Natural Hazards, 104, 2369-2387, https://doi.org/10.1007/s11069-020-04276-2, 2020.

605 Yun, X., Tang, Q., Wang, J., Liu, X., Zhang, Y., Lu, H., Wang, Y., Zhang, L., and Chen, D.: Impacts of climate change and reservoir operation on streamflow and flood characteristics in the Lancang-Mekong River Basin, Journal of Hydrology, 590, 125472, https://doi.org/10.1016/j.jhydrol.2020.125472, 2020.

Zhang, S. and Gao, H.: Using the digital elevation model (DEM) to improve the spatial coverage of the MODIS based reservoir monitoring network in South Asia, Remote Sensing, 12, 745, https://doi.org/10.3390/rs12050745, 2020.

610 Zhang, S., Gao, H., and Naz, B. S.: Monitoring reservoir storage in South Asia from multisatellite remote sensing, Water Resources Research, 50, 8927-8943, https://doi.org/10.1002/2014wr015829, 2014. 
https://doi.org/10.5194/hess-2021-360

Preprint. Discussion started: 5 August 2021

(C) Author(s) 2021. CC BY 4.0 License.

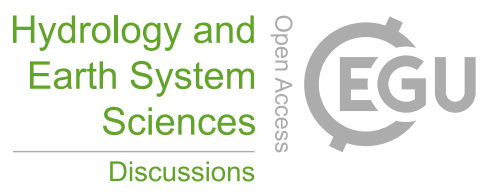

Zhang, Y., Erkyihum, S. T., and Block, P.: Filling the GERD: Evaluating hydroclimatic variability and impoundment strategies for Blue Nile riparian countries, Water International, 41, 593-610, https://doi.org/10.1080/02508060.2016.1178467, 2016.

Zhao, G. and Gao, H.: Automatic correction of contaminated images for assessment of reservoir surface area dynamics, Geophysical Research

Letters, 45, 6092-6099, https://doi.org/10.1029/2018g1078343, 2018. 